\title{
Physiology and Morphology of Color-Opponent Ganglion Cells in a Retina Expressing a Dual Gradient of $S$ and $M$ Opsins
}

\author{
Lu Yin, ${ }^{1}$ Robert G. Smith, ${ }^{1}$ Peter Sterling, ${ }^{1}$ and David H. Brainard ${ }^{2}$ \\ Departments of ${ }^{1}$ Neuroscience and ${ }^{2}$ Psychology, University of Pennsylvania, Philadelphia, Pennsylvania 19104
}

\begin{abstract}
Most mammals are dichromats, having short-wavelength-sensitive (S) and middle-wavelength-sensitive (M) cones. Smaller terrestrial species commonly express a dual gradient in opsins, with $\mathrm{M}$ opsin concentrated superiorly and declining inferiorly, and vice-versa for $S$ opsin. Some ganglion cells in these retinas combine S- and M-cone inputs antagonistically, but no direct evidence links this physiological opponency with morphology; nor is it known whether opponency varies with the opsin gradients. By recording from $>3000$ ganglion cells in guinea pig, we identified small numbers of color-opponent cells. Chromatic properties were characterized by responses to monochromatic spots and/or spots produced by mixtures of two primary lights. Superior retina contained cells with strong $S+/ M-$ and $M+/ S-$ opponency, whereas inferior retina contained cells with weak opponency. In superior retina, the opponent cells had well-balanced M and $S$ weights, while in inferior retina the weights were unbalanced, with the $M$ weights being much weaker. The $M$ and $S$ components of opponent cell receptive fields had approximately the same diameter. Opponent cells injected with Lucifer yellow restricted their dendrites to the $\mathrm{ON}$ stratum of the inner plexiform layer and provided sufficient membrane area $\left(\sim 2.1 \times 10^{4} \mu \mathrm{m}^{2}\right)$ to collect $\sim 3.9 \times 10^{3}$ bipolar synapses. Two bistratified cells studied were nonopponent. The apparent decline in S/M opponency from superior to inferior retina is consistent with the dual gradient and a model where photoreceptor signals in both superior and inferior retina are processed by the same postreceptoral circuitry.
\end{abstract}

\section{Introduction}

Most mammals have short-wavelength-sensitive ( $S$ ) cones and one or two types of middle/long-wavelength-sensitive (M/L) cones (with some deviations, Jacobs, 1993; Peichl et al., 2001) (for review, see Peichl, 2005; also Arrese et al., 2006; Cowing et al., 2008). Inputs from $S$ and $M / L$ cones combine antagonistically to form the basis for blue-yellow color vision. In trichromatic and dichromatic primate retinas, S-ON:M/L-OFF opponency is conveyed by both small and large sparse bistratified ganglion cells, while M/L-ON:S-OFF opponency is conveyed by large sparse monostratified and S-midget ganglion cells (Dacey, 1993; Dacey and Lee, 1994; Ghosh et al., 1997; Calkins et al., 1998; Ghosh and Grünert, 1999; Silveira et al., 1999; Dacey and Packer, 2003; Klug et al., 2003; Schein et al., 2004; Dacey et al., 2005; Martin et al., 2007). In other dichromatic mammals, physiological measurements reveal S/M opponent

\footnotetext{
Received Nov. 12, 2008; revised Jan. 6, 2009; accepted Jan. 15, 2009.

This work was supported by National Eye Institute Grants EY10016, EY08124, EY016607, and P30 EY001583. The data are also presented as part of the first author's Ph.D. thesis (L. Yin, 2008, unpublished Ph.D. thesis, Neuroscience Graduate Group, University of Pennsylvania). We thank Noga Vardi, Ying Xu, and Marie Fina for providing advice on immunostaining, confocal imaging, and quantification of dendritic morphology; Michael Freed for sharing data on the classification of guinea pig ganglion cells; Edward Pugh and Peter H. Li for useful discussions on a proposed quantitative model; John Andrews-Labenski, Michael Suplick, Fred Letterio, and Jian Li for technical assistance; and Sharron Fina for manuscript preparation.

Correspondence should be addressed to Dr. David H. Brainard, Department of Psychology, University of Pennsylvania, Suite 302C, 3401 Walnut Street, Philadelphia, PA 19104. E-mail: brainard@psych.upenn.edu.

DOI:10.1523/JNEUROSCI.5471-08.2009

Copyright $\odot 2009$ Society for Neuroscience $\quad$ 0270-6474/09/292706-19\$15.00/0
}

ganglion cells (Cleland and Levick, 1974; Caldwell and Daw, 1978; Ekesten et al., 2000; Grivich et al., 2005). These measurements, however, do not link the physiologically opponent cells to morphologically defined cell types. Based on anatomy it has been suggested that for rabbit, bistratified ganglion cells such as the G3 might correspond to the bistratified opponent ganglion cells in primate and thus carry S-ON:M-OFF signals (Rockhill et al., 2002). To clarify the nature of color vision in a nonprimate dichromatic mammal, we studied the morphology and physiology of opponent ganglion cells in guinea pig.

In guinea pig superior retina, each cone expresses either $\mathrm{S}$ or $\mathrm{M}$ opsin exclusively, and $\mathrm{S}$ cones comprise $\sim 6 \%$ of all cones (Röhlich et al., 1994; Yin et al., 2006). This expression pattern is typical of many dichromatic mammals (Jacobs, 1993; Szél et al., 1996; Ahnelt and Kolb, 2000; Szél et al., 2000; Peichl, 2005; Schiviz et al., 2008). Therefore, we asked whether the S+/Mganglion cells bistratify (as in primate), sending dendrites to both ON and OFF layers of the IPL. The inferior retina of guinea pig expresses mostly $\mathrm{S}$ opsin, and the small fraction of $\mathrm{M}$ opsin is found in cones that coexpress both opsins (Röhlich et al., 1994; Yin et al., 2006). Therefore, we asked whether this region contains color-opponent ganglion cells at all, and if so, whether the strength of opponency reflects the gradient of opsin expression.

We recorded from ganglion cells via loose-patch electrode and tested for color opponency. Opponency proved rare, occurring in $<1 \%$ of all cells tested. We characterized opponent cell spectral properties by measuring the response to flashed 

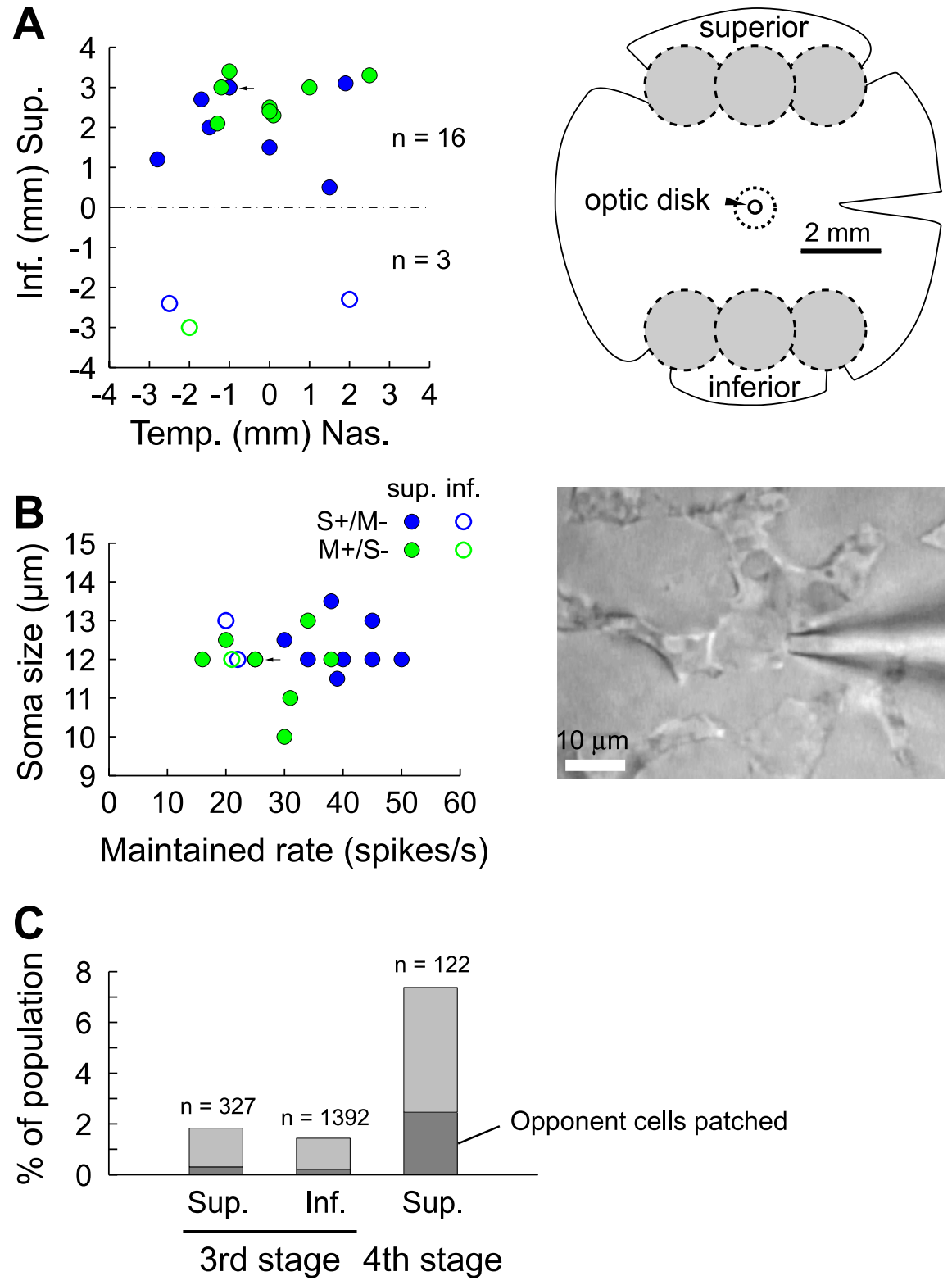

Figure 1. S/M opponent cells are present in superior and inferior retina. $\boldsymbol{A}$. Right, Regions searched. Left, Locations of all opponent cells relative to optic disk. Cells in superior and inferior retina are plotted as solid and open circles respectively. The $\mathrm{S}+/ \mathrm{M}-$ and $\mathrm{M}+/ \mathrm{S}-$ opponent cells are plotted in blue and green. Three cells identified in superior retina lie closer to optic disk $(<2 \mathrm{~mm})$ than the shaded circles shown in the right panel. One was encountered during an earlier experiment and the other two were encountered in the first experimental stage, when we periodically broadened the search region (see Materials and Methods). The arrow indicates where two $S+/ M-$ cells from superior retina plot to the same location. One $M+/ S-$ cell from superior retina which was found in the first stage is not plotted, because data on its location were not available. B, Right, An S+/Mopponent cell from superior retina in loose-patch configuration (DIC optics). Left, Soma sizes (estimated along the minor axis) versus maintained discharge rates in steady light. The arrow indicates where two $M+/ S-$ cells from superior retina plot to the same location. Same cells as in $\boldsymbol{A}$. C, Proportions of opponent cells encountered in the third and fourth experimental stages (see Materials and Methods). Of all the ganglion cells patched that met the anatomical screening criteria, the percentage of cells that also met the physiological screening criterion are shown as the combined height of light and dark bars. The light bars represent cells that were nonopponent, or responded weakly or not at all to contrast. The dark bars represent opponent cells. The numbers of cells for the light bars and the dark bars from left to right were as follows: 5 and 1,17 and 3 , and 6 and 3 . Total numbers of cells that met the anatomical criterion for each population are indicated above the bars. Not indicated in the figure is the fact that we also patched 15 cells in inferior retina in stage four, none of which were opponent. One of these 15 cells met our physiological screening criteria.

monochromatic spots and/or spots produced by mixtures of primary lights. Then we replaced the recording electrode with a sharp electrode and filled the cell with Lucifer yellow to reveal the dendritic arbor. We found both $\mathrm{S}+/ \mathrm{M}-$ and
$\mathrm{M}+/ \mathrm{S}$ - cells; both types were monostratified with flat arbors restricted to the IPL's ON stratum. Opponent cells were found in both superior and inferior retina. Across the retina, the strength of opponency changed with the change in proportion of S and M opsins.

\section{Materials and Methods}

Tissue preparation. We used albino guinea pigs weighing $300-700 \mathrm{~g}$. An animal was overdosed with anesthetic (ketamine $100 \mathrm{mg} / \mathrm{kg}$; xylazine $20 \mathrm{mg} / \mathrm{kg}$ and pentobarbital $50 \mathrm{mg} / \mathrm{kg}$ ) and both eyes were removed and hemisected. The eyecup was cut radially and flattened onto a membrane filter with ganglion cells up. This preparation was placed into a chamber on a microscope stage (BX50WI, Olympus America) and superfused with oxygenated $\left(95 \% \mathrm{O}_{2}\right.$ and $5 \% \mathrm{CO}_{2}$ ) Ames medium (Sigma) containing sodium bicarbonate $(1.9 \mathrm{~g} / \mathrm{L})$ and glucose $(0.8$ $\mathrm{g} / \mathrm{L}$ ) at $\sim 5-7 \mathrm{ml} / \mathrm{min}$. The chamber temperature was maintained between 34 and $37^{\circ} \mathrm{C}$. The retina was dark adapted for $0.5 \mathrm{~h}$ before measurements were made.

To help find particular retinal regions during the experiment, holes were cut in the membrane filter (Fig. 1A). When the tissue was flattened onto the filter, the small central hole $(0.8-1 \mathrm{~mm}$ diameter $)$ was positioned over the optic disk and the filter was oriented so that the other two elongated holes were located above or below the optic disk. The middle of each region was aligned along the superior-inferior axis of the tissue through the optic disk ( $3 \mathrm{~mm}$ superior or inferior to the optic disk). Recordings were made mainly from within these regions. In the first experimental stage of the study (defined below), recordings were also made from regions in superior retina closer to the optic disk. Retinal locations of the recording sites were measured relative to the optic disk.

Electrical recording. Ganglion cells were identified for recording by observing the tissue through the infrared differential interference contrast (DIC) optics of the microscope (Fig. $1 B$, right panel) with a $60 \times(0.9 \mathrm{NA})$ objective. Cells were recorded extracellularly with loose patch electrodes (tip impedance $=$ 2-4 M $\Omega$ ). Responses were amplified (NeuroData IR-283, Cygnus Technology), digitized at a $5 \mathrm{kHz}$ sampling rate with 12 -bit precision (DigiData 1200, Molecular Devices), and stored for later analysis (AxoScope, Molecular Devices). Spikes were identified using a threshold detection method. Spike rates were calculated for $\sim 15 \mathrm{~ms}$ bins.

Searching for S/M opponent cells. To search for $\mathrm{S} / \mathrm{M}$ opponent cells, we went through four experimental stages for a total of 66 experiments, adopting different search strategies in each stage. In the first stage $(n=17$ experiments), we began by patching ganglion cells in superior retina and testing every cell for opponency (see below for a description of the opponency test). In targeting cells for patching we excluded brisk-transient ganglion cells, which could be identified because of their large soma size, but otherwise patched all cells encountered. Later analysis revealed that the 
patched cells generally had soma sizes between 10 and $15 \mu \mathrm{m}$, with a few as large as $18 \mu \mathrm{m}$ (Fig. $1 \mathrm{~B}$, left) (soma size was typically estimated along the minor axis). We patched $>145$ cells in the first stage and encountered three opponent cells. Before the first stage, in experiments conducted as part of a separate study, one additional opponent cell was encountered near the superior region of the transition zone, where some M cones coexpress S opsin (Röhlich et al., 1994). We include that cell here (Fig. $1 \mathrm{~A}$, blue solid circle closest to middle line in left panel; morphology in the third panel from top in Fig. 7A).

For the opponent cells encountered in the first stage, we observed certain anatomical and physiological properties in common. For example, they tended to have a medium soma size and high maintained discharge rate in light. We took those properties as predictive of whether a ganglion cell would be opponent in stage two of the experiments.

In stage two ( $n=26$ experiments), we searched for ganglion cells in superior retina that matched the properties described above and only took the time to test for opponency when a cell matched these qualitative selection criteria. As we encountered more opponent cells $(n=9$ more cells in stage two, out of $>1085$ cells patched), we gradually refined the qualitative selection criteria. These observations led us to develop quantitative screening criteria for identifying $\mathrm{S} / \mathrm{M}$ opponent cells in superior retina: (1) medium soma size, ranging between 10 and $14 \mu \mathrm{m}$ and (2) high maintained discharge rates to a uniform background (main background, see below; $>15$ spikes/s), and also moderate to high maintained rates in the dark ( $>5$ spikes/s). All opponent cells encountered in this study satisfied these criteria (Fig. $1 B$, left panel; maintained rates in dark are not shown, as they were not measured for some of the opponent cells in the first stage). Criterion (1) was based on anatomy and was met by a high percentage of ganglion cells (visual observation; Do-Nascimento et al., 1991). Criterion (2) was based on physiology and was met only by a very small percentage of ganglion cells (see Fig. $1 C$ ). In our experience, most ganglion cells had a maintained rate to the main background of $\leq$ 10 spikes/s. We also studied $>41$ cells from inferior retina in stage 2 , without encountering an opponent cell.

In stages one and two we were focused on finding opponent cells and developing a sense of their general properties. We did not in these exploratory stages keep explicit records of every nonopponent cell patched. The reported numbers (145 for superior retina in stage one, 1085 for superior retina in stage 2, 41 for inferior retina for stage 2 ) are the number of cells explicitly documented, and represent a lower bound on the number of cells actually patched.

In the third stage ( $n=18$ experiments), we applied the screening criteria developed in stage two for experiments conducted in both superior and inferior retina. We only patched ganglion cells with appropriate soma size. Of all the cells patched in superior retina (327 cells, 1 opponent), we tried to study in detail those that had appropriate maintained rates and were opponent (Fig. $1 C$, left and middle bars). Of all the cells patched in inferior retina ( 1392 cells, 3 opponent), we tried to study every cell with appropriate maintained rates, except those that responded weakly or not at all to contrast (Fig. 1C, middle bars). We occasionally studied cells whose maintained rates fell below the cutoffs we established and none of those cells were opponent.

The final experimental stage (stage four) was designed to check whether the physiological screening criteria might have excluded a major population of opponent cells. In this stage ( $n=6$ experiments), we tested every cell patched in superior retina for opponency, and studied all of the opponent cells encountered ( $n=3$, out of 122 cells patched). All of the opponent cells identified in this stage satisfied the criteria established in stage two (Fig. 1C, right bars). We also patched 15 cells in inferior retina during this stage, none of which were opponent.

Characterizing chromatic response properties of ganglion cells. Chromatic response properties of ganglion cells were characterized by recording responses to spots of different spectral composition. "Flicker experiments" measured responses to spots on a spatially uniform background. These spots were produced by modulating mixtures of two primary lights. This method provided an efficient way to assess whether a cell was opponent, and to estimate the spatial extent of its receptive field. We used this method, as described above, to identify S/M opponent cells. "Flash experiments" were designed to provide a quantitative characterization of a cell's opponency. These experiments measured responses to flashed monochromatic spots on a spatially uniform background. This method was slow but allowed direct characterization of the spectral properties of a ganglion cell. We used this method not only to verify that a cell was opponent, but also to measure the relative strengths of $\mathrm{M}$-cone, $\mathrm{S}$-cone, and rod inputs (M and S and rod "photopigment weights").

We used the same two optical systems as in our previous study (Yin et al., 2006). Briefly, (1) "LCD system," light from an LCD projector (PowerLite 730c, Epson America) produced images that subtended $\sim 2.4 \times 3.2$ $\mathrm{mm}$ on the retina, with each pixel corresponding to $\sim 3.1 \times 3.1 \mu \mathrm{m}$. (2) "Lamp system," light from a xenon lamp (HLX 64642, Osram), collimated and fed through a tunable narrowband filter (VariSpec, Cambridge Research \& Instrumentation) and an adjustable aperture produced a uniform spot of monochromatic light ( $\sim 10 \mathrm{~nm}$ bandwidth) on the tissue. The temporal profile of the spot was controlled by a mechanical shutter (VS25S2T1 shutter and 122-BP controller, Uniblitz). The outputs of the two optical systems were combined through a beamsplitter and delivered to the tissue through the camera port on the microscope and the objective $(4 \times)$. Full details of the configurations of the two systems, and on spectral characterization and calibration, are reported in Yin et al. (2006). As the original lamp system did not produce sufficient light intensity at $430 \mathrm{~nm}$ for this study we expanded the lamp system with another channel, which was fed through a narrowband interference filter of $430 \mathrm{~nm}$.

The flicker experiments used the LCD system alone to modulate a spot $(\sim 100-1600 \mu \mathrm{m}$ diameter) around the background at $2-4 \mathrm{~Hz}$ (sinusoidal temporal waveform). The main background produced nearly equal isomerization rates in $\mathrm{M}$ and $\mathrm{S}$ cones (4.06-4.17 and 4.01-4.12 $\log _{10}$ $\mathrm{Rh}^{\star} /$ photoreceptor/s) and a somewhat higher rate in rods (4.65-4.76 $\log _{10} \mathrm{Rh}^{\star} /$ photoreceptor/s). The exact background intensities are noted in the text where necessary. In the earlier experiment (described above, one opponent cell), a CRT instead of the LCD projector was used in the optical system. The background used in that experiment produced isomerization rates of $3.99(\mathrm{M}), \quad 3.53$ (S), 4.44 (Rod) $\log _{10}$ $\mathrm{Rh}^{\star} /$ photoreceptor/s.

Reported isomerization rates were computed as described by Yin et al. (2006), based on parameters estimated for intact guinea pig retina. In our in vitro preparation, the basic orientation of the receptors with respect to the incident light was the same as for intact retina, but detailed differences in orientation could produce deviations between computed and actual isomerization rates. We did not correct for any such differences. Note that our analyses of cell properties are not sensitive to a change in scaling of the computed isomerization rates, since these were based on contrast.

Ganglion cells were adapted continuously throughout the recording. To screen a cell for opponency, a sequence of flickering spots modulated along $\mathrm{M}$-cone and S-cone isolating directions as well as in $\mathrm{M}+\mathrm{S}$ and $\mathrm{M}-\mathrm{S}$ color directions was repeated (typical stimulus parameters: $\sim 800 \mu \mathrm{m}$ in diameter, temporal frequencies of 2 or $4 \mathrm{~Hz}$, duration of $8 \mathrm{~s}$ for each direction). The spike traces and voltage pulses marking the start and end of each modulation cycle were visualized using AxoScope (Molecular Devices). From the relative response amplitudes and phases to modulations along the four color directions, we could determine whether a cell was opponent. The characteristics of S/M opponent cells were that (1) they responded to modulations along both $\mathrm{M}$ - and S-cone isolating directions, but with opposite response polarities and (2) they responded strongly to modulation along the $\mathrm{M}-\mathrm{S}$ opponent direction but weakly to the $\mathrm{M}+\mathrm{S}$ nonopponent direction (Fig. 2A). Nonopponent ganglion cells responded with the same polarity to modulation along both $\mathrm{M}$-cone and S-cone isolating directions, and more strongly to modulation along the $\mathrm{M}+\mathrm{S}$ nonopponent direction than the $\mathrm{M}-\mathrm{S}$ opponent direction. In some experiments, to test cells for opponency as efficiently as possible, the flickering stimulus was presented directly through the $60 \times$ objective instead of $4 \times$ objective. This reduced the size of the stimulus. We did not perform a separate spectral calibration for the $60 \times$ objective.

We recorded the spike responses to flickering spots of ganglion cells 
A
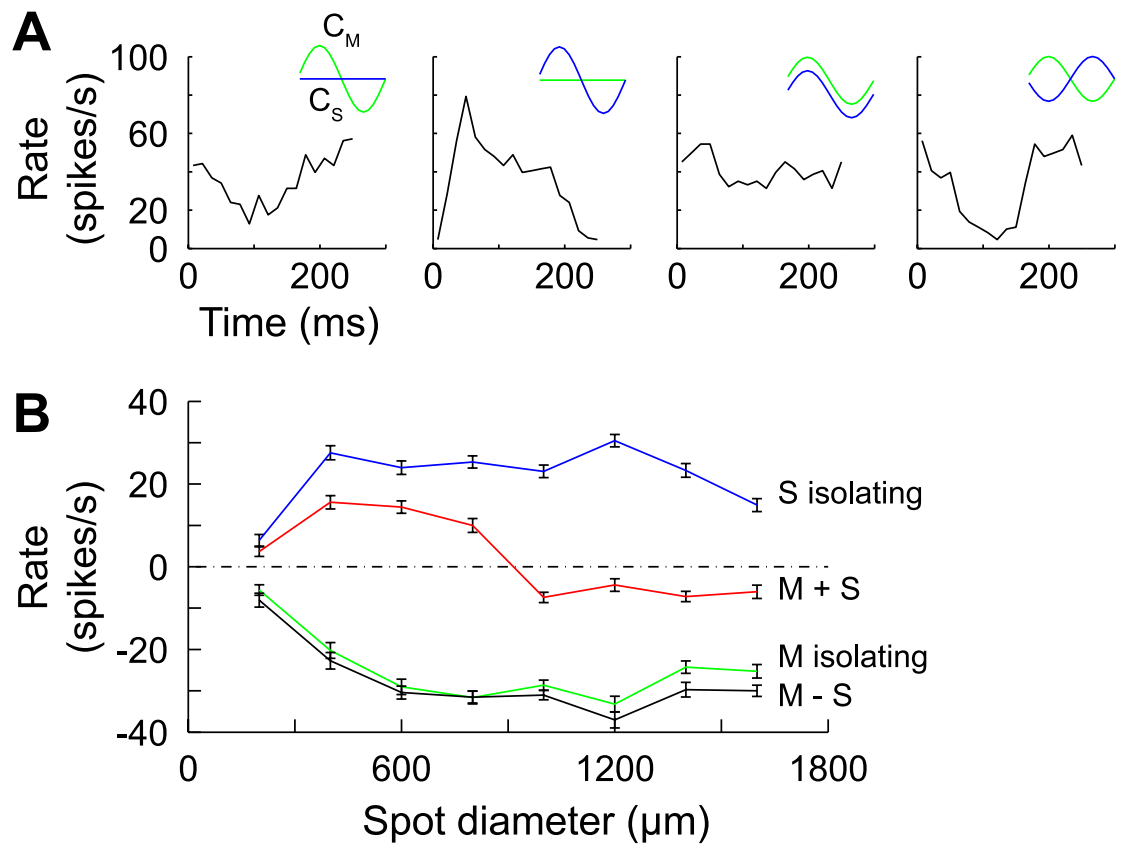

C
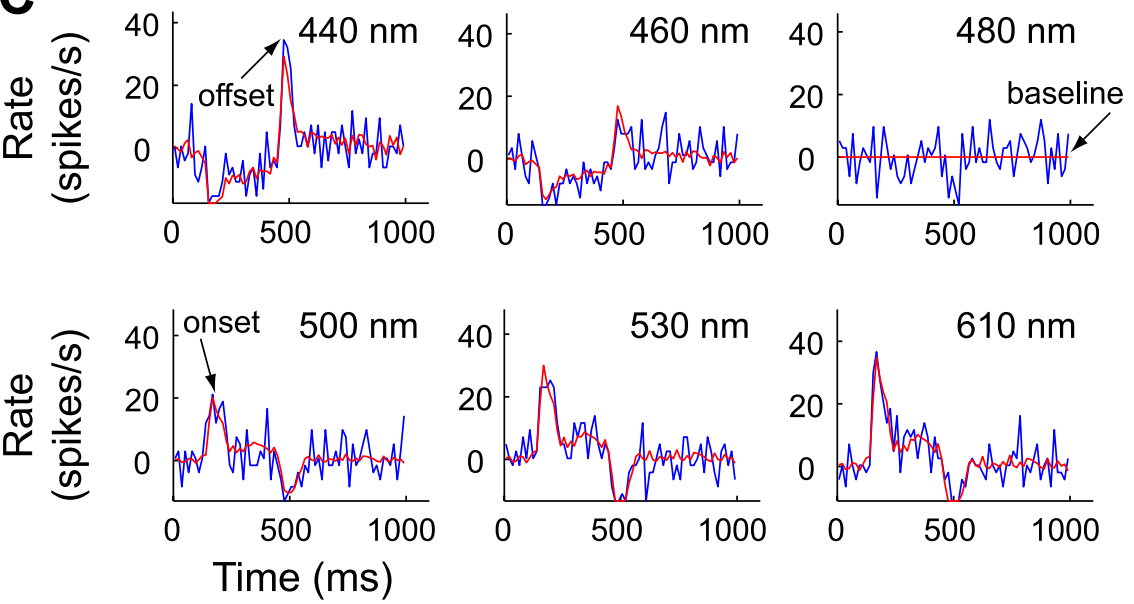

Figure 2. S/M opponent cells characterized by flickering and flashed monochromatic spots. $A$, Opponency test using flickering spots. All panels show the responses (PSTH, dark lines) of an $S+/ M-$ opponent cell in superior retina to flickering spots (diameter $800 \mu \mathrm{m}$; temporal frequency $\sim 4 \mathrm{~Hz}$ ) modulated along $\mathrm{M}$-cone and S-cone isolating directions, as well as in $\mathrm{M}+\mathrm{S}$ and $\mathrm{M}-\mathrm{S}$ color directions. Temporal waveforms of the four modulations (green and blue lines) are shown in the insets of each plot. The $M$ and $S$ cone contrasts, $\left[C_{M}, C_{S}\right]$, of the four modulations were (from left to right): [35\%, 0\%], [0\%, 35\%], [25\%, 25\%], and [24\%,-24\%]. $\boldsymbol{B}$, Spatial structure of the receptive field. Same cell as in $\boldsymbol{A}$. The plot shows the signed response amplitude (F1 \pm SEM) to modulations in the same four color directions used in $\boldsymbol{A}$, measured in another block of trials, where the spot diameter was varied from 200 to $1600 \mu \mathrm{m}$. $C$, Response to flashed monochromatic spots. All panels show the responses (PSTHs, in blue) of an $M+/ S-$ opponent cell in superior retina to flashed monochromatic spots (diameter $\sim 850 \mu \mathrm{m}$; flash duration $300 \mathrm{~ms}$ ). This cell responded to flashed monochromatic spots of short and middle/long wavelengths with opposite response polarities; the morphology of this cell shown in the third panel from the top in Figure $7 B$. Stimulus onset was at $100 \mathrm{~ms}$. PSTHs were fitted (red lines) with a template (Appendix A). PSTHs and fits were shifted vertically to align the fitted baseline rate with zero spikes/s.

identified as opponent by the screening procedure (typical stimulus parameters: $800 \mu \mathrm{m}$ in diameter, temporal frequency of $4 \mathrm{~Hz}$, duration of $32 \mathrm{~s}$ for each direction). The number of contrasts presented for each color direction (M-isolating, S-isolating, $\mathrm{M}+\mathrm{S}, \mathrm{M}-\mathrm{S}$ ) varied from cell to cell. For some cells, we also recorded area summation data in the form of responses to flickering spots of diameters between 100 and $1600 \mu \mathrm{m}$ (Figs. 2 B, 9; supplemental Fig. 1, available at www.jneurosci.org as supplemental material). For quantitative analysis, the response was taken as the signed fundamental response amplitude (F1) of the peristimulus time histogram (PSTH), with the sign of the response indicating whether the fundamental was best described as in-phase or out-of-phase with the stimulus modulation (after accounting for response delay). Responses during the first and last stimulus cycles were excluded from the analysis.

The flash experiments used monochromatic spots from the lamp system on a background produced by the LCD system. The main background was the same that used for the flicker experiments, and cells were adapted continuously throughout the recording. A sequence of flashed monochromatic spots of wavelengths between 430 and $620 \mathrm{~nm}$ was presented. We refer to the presentation of a series of flashed monochromatic spots at one wavelength as a "trial," and to the presentation of a sequence of trials for different wavelengths as a "block"; stimulus parameters: $800-900 \mu \mathrm{m}$ diameter, flash duration of $300 \mathrm{~ms}$ at $1 \mathrm{~s}$ intervals $(500 \mathrm{~ms}$ for two cells), 12-32 repetitions per trial, and 19-30 trials per block.

The spike traces and voltage traces marking the flash onset and offset were visualized using AxoScope (Molecular Devices) and fed to an audio-speaker for real time monitoring. From the response polarities to monochromatic flashes at short, middle, and long wavelengths we could decide whether a cell was opponent. The characteristics of S/M opponent cells were that (1) they had spectral neutral points, that is a wavelength range where they responded only weakly to monochromatic flashes and (2) they responded to monochromatic flashes of wavelengths longer or shorter than spectral neutral points with opposite response polarities.

As the PSTHs were noisy, we derived fits to each individual PSTH using a template method and extracted the response amplitudes from the fits (Appendix A). Responses were taken as the peak of spike rate increment from baseline at either the flash onset or offset (Fig. 2C). We report photopigment weights derived from spectral measurements for seven opponent ganglion cells and one possibly opponent ganglion cell (see Results) (Fig. 6). We report spectral neutral points for five additional cells where full spectral characterization was not possible (see Results) (Fig. 3). Stimulus parameters for these cells were the same, except that one was studied with a $2000-\mu \mathrm{m}$-diameter spot.

Estimating photopigment weights. From the responses to monochromatic spots, we could estimate the relative strength of $\mathrm{M}, \mathrm{S}$, and rod inputs to a ganglion cell. Appendix B describes the linear-nonlinear (LNL) model we used to estimate contrast-response nonlinearities, action spectra, and photopigment weights. The responses of all nine ganglion cells where we had sufficient flash data to perform this analysis were well-described by the LNL model. For these cells, the maximal cone or rod contrasts presented (across wavelengths) were $<120 \%$ for three cells, $150 \%$ for three cells, $200 \%$ for one cell, $250 \%$ for one cell and $350 \%$ for one cell.

Dye staining, immunostaining, and quantitative morphology. After recording, some ganglion cells were penetrated with a sharp electrode and stained with Lucifer yellow ( $3 \%$, in $0.1 \mathrm{M} \mathrm{LiCl}$ solution; Invitrogen) to visualize their morphology. To verify that the cell stained was the one recorded, DIC views of the cell soma were captured before the loose patch electrode was released and after the sharp electrode was positioned near 


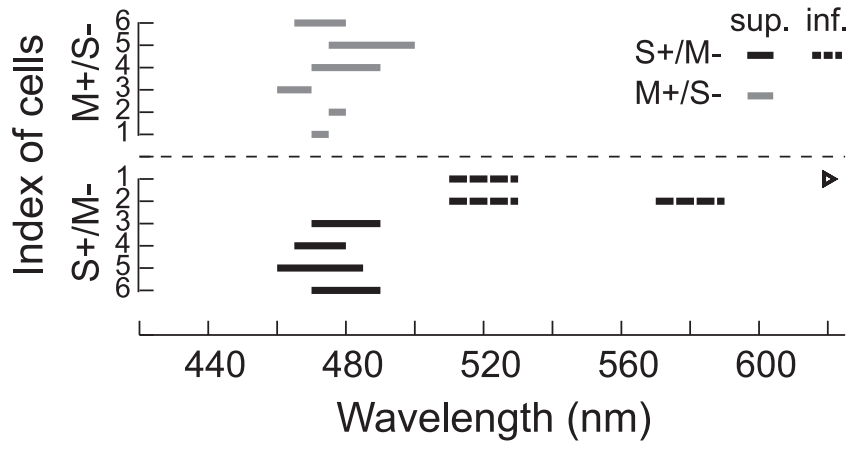

Figure 3. Spectral neutral points of $S / M$ opponent cells vary across retina. Spectral neutral points are indicated by horizontal lines. At wavelengths within each horizontal line, the cell responded with indeterminate response polarity; at the wavelengths indicated by the lines' ends the cell responded with clear and opposite polarities. For cells in superior retina (solid lines), data were combined across multiple blocks. For cells in inferior retina (dashed lines), measurements from the individual blocks are shown separately. Measurements for $S+/ M-$ and $M+/ S-$ opponent cells are presented below and above the dashed black line, and are also distinguished by being shown with black and gray bars respectively. For $S+/ M-$ opponent cell 1 , the second block of trials did not reveal a spectral neutral point within the wavelength range we measured (triangle). Photopigment weights for a subset of cells $(S+/ M-$, index 1,2 , and $3 ; M+/ S-$, index $1,2,5$, and 6) are shown in Figures $4 C, 4 F, 5 C$, and 6.

the soma. After staining, the tissue was fixed in $4 \%$ paraformaldehyde in $0.1 \mathrm{M}$ phosphate buffer $(\mathrm{PB})$ for $1 \mathrm{~h}$ in dark and store in $\mathrm{PB}$ in $4 \mathrm{C}^{\circ}$ before immunostaining.

After a brief wash in $\mathrm{PB}$, the retina was peeled from the pigment epithelium and incubated in blocking buffer (10\% normal goat serum, $5 \%$ Triton X-100 in PB with 5\% sucrose) for $1 \mathrm{~h}$ to reduce nonspecific binding. We reacted the retina with primary antibodies to Lucifer yellow to enhance the staining of the dendrites of the ganglion cell, and to $S$ opsin to reveal the overlaying S-cone mosaic. For Lucifer yellow we used rabbit anti-Lucifer yellow (Invitrogen) at a dilution of 1:500 and for $S$ opsin we used rabbit anti-S opsin (Millipore Bioscience Research Reagents) at a dilution of 1:600. The reaction was carried out initially at room temperature for $2 \mathrm{~h}$, then at $4 \mathrm{C}^{\circ}$ for $35 \mathrm{~h}$. After several washes in $\mathrm{PB}$ with $5 \%$ sucrose (SPB), we reacted the retina with secondary antibodies to visualize the primary antibody staining ( $4 \mathrm{~h}$, at room temperature). Both the dendrites of the ganglion cell and S opsin were tagged with FITC or CY3 (Invitrogen). After several washes in SPB, we reacted the tissue with SYTO 61 or SYTO 13 nucleic acid stains (Invitrogen) to visualize the amacrine cell layer (ACL) and the ganglion cell layer (GCL), which outlined the boundaries of the IPL. Finally after several washes in SPB, we mounted the retina on a glass slide with the ganglion cell side up and covered it with mounting medium (Vectashield, Vector Laboratories) and a coverslip.

The tissue was examined using a confocal microscope (Leica TCSNT, Leica) with $10 \times(0.3 \mathrm{NA}), 40 \times(1.25 \mathrm{NA})$, and $100 \times(1.4 \mathrm{NA})$ objectives. Image stacks were obtained at two $\mathrm{z}$-depths, with one covering IPL, including the stained ganglion cell and another one covering the photoreceptor layer, including the S-cone outer segments. To quantify the dendritic morphology of a ganglion cell: (1) we estimated the diameter of the dendritic field from the tangential view at $20 \times(10 \times$ objective with $2 \times$ magnification; $500 \times 500 \mu \mathrm{m})$. We drew a polygonal contour connecting the most distal dendritic tips and then fit the polygon with an ellipse using the NIH Image software (http://rsb.info.nih.gov/nih-image/). The estimated diameter was the average length of the major and minor axis of the fitted ellipse. (2) We measured the length of the ON or OFF dendrites from the tangential image stack at $40 \times(250 \times 250 \mu \mathrm{m})$ by tracing all dendrites in $3 \mathrm{D}$ using the Volocity software (Improvision). The density of the ON dendritic processes was calculated by dividing the length of ON dendrites by the area of the polygon containing all the $\mathrm{ON}$ dendrites in the same view. This density is one of the parameters that proved effective for morphological classification of ganglion cells in a cluster analysis reported by Kong et al. (2005). (3) We measured the relative depths of distal dendrites within IPL at several locations from the tangential image stack at $40 \times$ and sometimes $100 \times(250 \times$ $250 \mu \mathrm{m}$ ), also using the Volocity software. The depth of dendritic stratification was expressed as the percentage of the total depth of the IPL, starting from $0 \%$ at the boundary with the amacrine cell layer and ending with $100 \%$ at the boundary with the ganglion cell layer. To generate radial views, we resliced a section of $\sim 250 \times 60 \mu \mathrm{m}$ within the tangential image stack using the NIH Image software (see Figs. $7 A-C, 8 A)$.

We quantified the dendritic membrane area of opponent ganglion cells using a procedure similar to that described by Xu et al. (2008). First, we divided the tangential image stack obtained at $40 \times$ magnification into subregions: a circular region of $30 \mu \mathrm{m}$ diameter centered around the cell soma and a series of outward expanding concentric rings with equal widths of $25 \mu \mathrm{m}$. All of the image stacks analyzed had $x$ - and $y$-resolutions of $0.24 \mu \mathrm{m}$ and a $z$-resolution of $0.49 \mu \mathrm{m}$. One image stack (that shown in Fig. 7A, the third panel from top) was excluded because its z-resolution was larger than the diameters of typical distal dendrites. Second, after smoothing the images with $3 \times 3$ median filter, we used the Volocity software to recognize and reconstruct the dendrites contained in each of the ring subregions. Finally, we measured the dendritic membrane area from the reconstructed dendrites and calculated the dendritic membrane density by dividing the dendritic membrane area by the retinal area of corresponding ring.

\section{Results}

\section{Responses to modulations}

Figure $2 \mathrm{~A}$ shows responses from an $\mathrm{S}+/ \mathrm{M}-$ cell from superior retina to $4 \mathrm{~Hz}$ modulations of an $800 \mu \mathrm{m}$ spot. The responses clearly reveal the opponent nature of this cell. Responses to modulation along $\mathrm{M}$ - or S-cone isolating directions had opposite response polarities. The response to modulation along the $\mathrm{M}-\mathrm{S}$ opponent direction was strong, but that to the $\mathrm{M}+\mathrm{S}$ nonopponent modulation was weak. $\mathrm{M}+/ \mathrm{S}-$ opponent cells showed a similar response pattern, but with opposite response polarities.

Figure $2 B$ shows the dependence of the responses on spot size for the same cell. For $\mathrm{M}$-cone, $\mathrm{S}$-cone, and $\mathrm{M}-\mathrm{S}$ modulations, response amplitude increased with spot diameter and then remained fairly constant, indicating a lack of spatial antagonism for these modulation directions. For the $\mathrm{M}+\mathrm{S}$ modulation response first increased with diameter and then decreased, indicating a spatially antagonistic receptive field structure for this modulation direction. These measurements are qualitatively consistent with an S-ON center opposed by a slightly larger M-OFF surround (see Fig. 9A, second panel from top on the left). Figure 9 and supplemental Figure 1 (available at www.jneurosci.org as supplemental material) provide the full set of area summation measurements we made for opponent cells, along with quantitative model fits that provide estimates of their receptive field structure (see detailed discussion below; Appendix C). We checked for, and did not observe, changes in response phase with stimulus size (data not shown).

Spectral neutral points, action spectra, derived photopigment weights, and receptive field structure for cells identified as opponent by their responses to modulations are presented below. These include $\mathrm{S}+/ \mathrm{M}-$ and $\mathrm{M}+/ \mathrm{S}-$ cells in superior retina and $\mathrm{S}+/ \mathrm{M}-$ cells in inferior retina. We also encountered one $\mathrm{M}-/ \mathrm{S}+$ cell in inferior retina, as classified by its responses to flickering $\mathrm{M}$-isolating, $\mathrm{S}$-isolating, $\mathrm{M}+\mathrm{S}$, and $\mathrm{M}-\mathrm{S}$ modulations. We were not able to hold this cell long enough to characterize further its physiology, nor were we able to fill it and obtain its morphology. 


\section{Spectral neutral points of S/M opponent cells}

The response polarities of S/M opponent cells to flashed monochromatic spots varied with wavelength, depending on the relative strengths of the excitatory input from one cone type and the inhibitory input from another cone type (Figs. $2 C, 4 A, D, 5 A)$. At the spectral neutral points, where the excitatory and inhibitory inputs balanced each other, response polarities were indeterminate (Fig. 2C, PSTH for $480 \mathrm{~nm}$ ). For $\mathrm{S}+/ \mathrm{M}-$ opponent cells, at wavelengths shorter than the spectral neutral points, the response polarities were ON, reflecting the dominant S-ON $(\mathrm{S}+)$ input. At wavelengths longer than the spectral neutral points, the response polarities were OFF, reflecting the dominant $\mathrm{M}-\mathrm{OFF}(\mathrm{M}-)$ input. The $\mathrm{M}+/ \mathrm{S}-$ opponent cells showed the reverse pattern.

All S/M opponent cells in superior retina had similar spectral neutral points, for both $S+/ \mathrm{M}-(n=4)$ and $\mathrm{M}+/ \mathrm{S}-(n=$ 6) types (Fig. 3). The neutral points were similar to those determined behaviorally for guinea pig (Jacobs and Deegan, 1994).

$\mathrm{S}+/ \mathrm{M}-$ opponent cells in inferior retina $(n=2)($ Fig. 3$)$ had spectral neutral points at longer wavelengths than those in superior retina. For one cell, the opponency which had been apparent in the flicker screening measurements and in the first block of flash trials was absent in the second block of trials (Fig. 3, triangle). That the spectral neutral points occur at longer wavelengths for cells from inferior retina is consistent with a decline in the relative strength of $\mathrm{M}$ input for $\mathrm{S} / \mathrm{M}$ opponent cells from superior to inferior retina. This decline was confirmed by the quantitative characterization of photopigment weights presented in the next section.

\section{Photopigment weights of S/M opponent cells}

We measured photopigment contributions to S/M opponent cells from their responses to monochromatic flashes (see Appendices A and B). Action spectra of opponent cells across retina were well fit with weighted sums of $\mathrm{M}, \mathrm{S}$, and rod spectral sensitivities (Figs. 4C,F, 5C). The nonlinearities in the contrast responses of each cell were also well described (Figs. $4 B, E, 5 B$ ). The overall shape of the action spectra for S/M opponent cells in superior retina resembled the increment-threshold spectral sensitivity functions measured behaviorally against an achromatic background [Jacobs and Deegan (1994), their Figs. 6, 7]. This suggests that $\mathrm{S} / \mathrm{M}$ opponent cells in superior retina subserve guinea pig color vision.

The action spectra can also be interpreted in terms of the $S$ and $\mathrm{M}$ photopigment weights. S/M opponent cells in superior retina had balanced inputs from $S$ and $M$ cones, for both $\mathrm{S}+/ \mathrm{M}-$ and $\mathrm{M}+/ \mathrm{S}-$ types. Correspondingly, in Figure 6 , the points representing photopigment weights of S/M opponent cells fell in the vicinity of the $-45^{\circ}$ or $135^{\circ}$ diagonals. Because $\mathrm{S}$ cones are much sparser in superior retina than $\mathrm{M}$ cones, the balanced weights indicate that signals from $S$ cones are selectively amplified.

$\mathrm{S} / \mathrm{M}$ opponent cells in inferior retina received unbalanced inputs from $\mathrm{M}$ and $\mathrm{S}$ photopigments, with the relative strength of the $M$ input was much weaker than that of the $S$ input (Fig. 5). Correspondingly, in Figure 6, the data points representing the photopigments weights for $\mathrm{S} / \mathrm{M}$ opponent cells in inferior retina were close to the $y$-axis, where the $\mathrm{M}$ weight equals zero. The cell that failed to show a spectral neutral point in the second block of trials (Fig. 3, triangle) still showed slight opponency for this block when the data were analyzed in terms of photopigment weights (Fig. 6, arrow).
One additional cell studied from inferior retina is worth comment. This cell met the anatomical screening criteria, but its maintained discharge rate fell below the screening cutoff we established. Still, we recorded from it, to learn whether it represented a novel cell type. This cell was monostratified in the ON stratum of the IPL. It was not opponent according to its responses to flickering stimuli, nor did it have a spectral neutral point in response to monochromatic flashed stimuli. For these reasons, we have not grouped this cell with the two $\mathrm{S}+/ \mathrm{M}-$ cells we identified in inferior retina. The quantitative analysis, however, did reveal weak $\mathrm{M}$ and $\mathrm{S}$ weights of opposite sign (Fig. 6, diamond) and it is possible that this cell represents a third exemplar of an $\mathrm{S}+/ \mathrm{M}-$ opponent cell.

As shown in Figure 6, the $\mathrm{S}$ weights of four S/M opponent cells decreased substantially during the course of experiments (connecting lines with arrows). It is possible that cone opsins were bleached under continuous light adaptation, although our retinal preparation was capable of regenerating bleached photopigments (see Materials and Methods). The finding in mouse that $\mathrm{S}$ cones are more susceptible to bleaching than $\mathrm{M}$ cones could then potentially explain our observation (Nikonov et al., 2006).

Photopigment weights of S/M opponent cells across retina (Fig. 6, solid and open circles) differed from those of horizontal cells measured at a similar background intensity [Yin et al. (2006), their Fig. 3], as well as from those of brisk-transient ganglion cells (see Fig. 11) [Yin et al. (2006), their Fig. 6], in two aspects. First, opponent cells in superior retina received much larger $S$ input than horizontal cells or brisk-transient ganglion cells in superior retina, and for the opponent cells the $S$ weight (absolute value: $0.37 \pm 0.17 \mathrm{SD}, n=5$ for both $\mathrm{S}+/ \mathrm{M}-$ and $\mathrm{M}+/ \mathrm{S}-$ types) (Fig. 11) was much larger than the percentage of $S$ cones in superior retina $(\sim 6 \%)$. This suggests that $S$ input to the opponent cells is processed by a retinal pathway with high relative gain. Presumably this pathway involves S-ON bipolar cells (Mariani, 1984; Kouyama and Marshak, 1992; Calkins et al., 1998; Haverkamp et al., 2005; Li and DeVries, 2006; MacNeil and Gaul, 2008). Second, opponent cells generally received smaller amounts of rod input than horizontal cells from the same retinal regions. This would be explained if rod signals reach S/M opponent cells through both of the $S$ and $M$ antagonistic pathways that drive the ganglion cell and thus tend to cancel. For all opponent cells where we could quantify the inputs, the rod weight was either negligible (absolute value $\leq 7 \%$ ) or else had the same sign as the Scone input (Fig. 6).

\section{Morphology of S/M opponent cells}

Based on the morphologies of well-stained opponent cells (Fig. 7), S/M opponent cells across retina were monostratified, either completely or primarily, in the IPL's ON stratum. This held for both $S+/ \mathrm{M}-$ (superior retina: $n=3$; inferior retina: $n=2$ ) and for $\mathrm{M}+/ \mathrm{S}-$ types (superior retina: $n=3$ ) (Fig. 7 ). Opponent cells from both superior and inferior retina were similar in terms of the parameters we used to quantify cell morphology: the diameter of the dendritic field, the depth of dendritic stratification and the density of the $\mathrm{ON}$ dendritic processes. Values for these parameters are provided in Table 1. There may, however, be small differences in aspects of the morphology that we did not quantify. For example the presence of very short lateral dendritic branches appeared more prominent in the cells from inferior retina (Fig. 7C, the third panel from top). We also obtained incomplete morphologies 

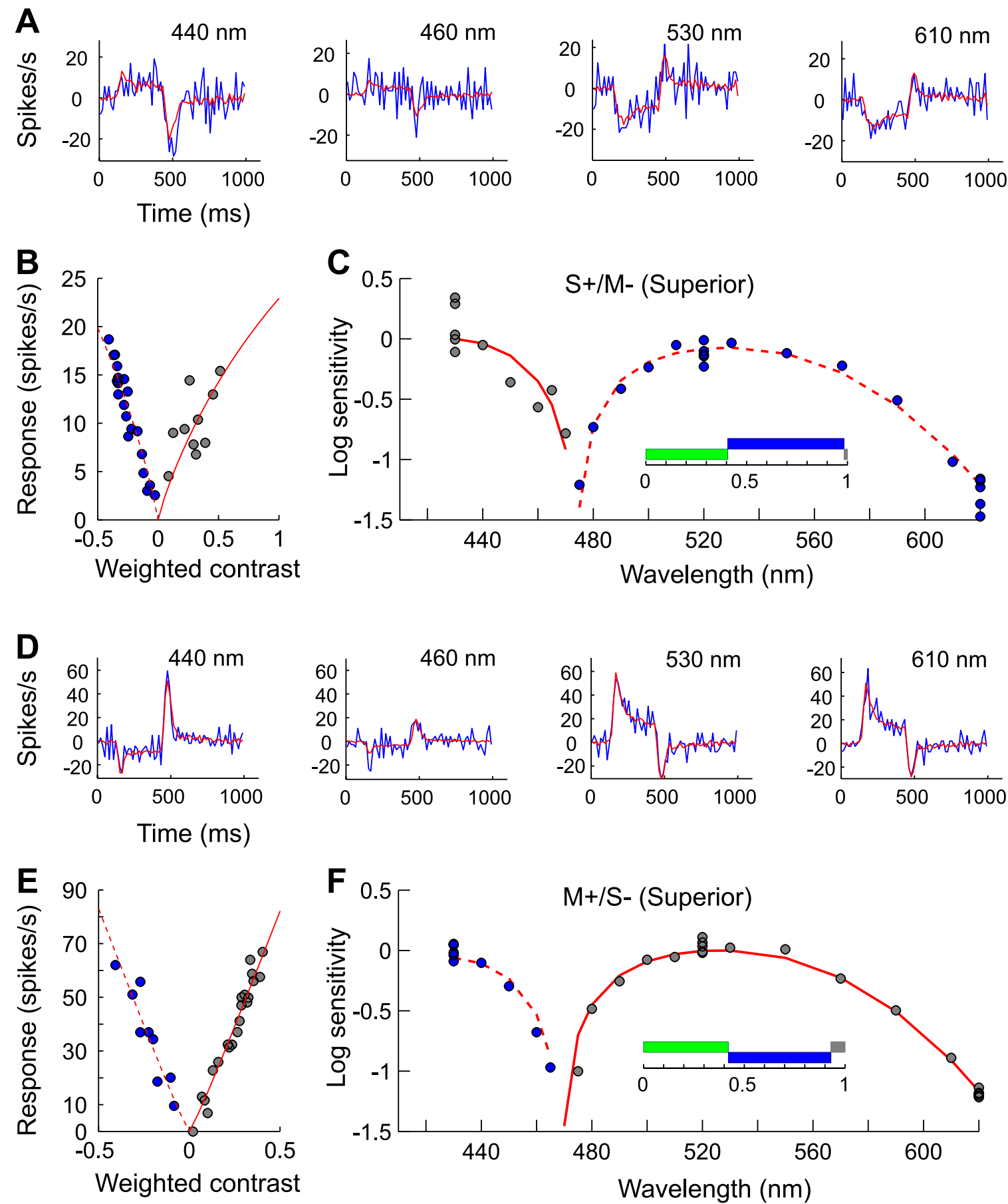

Figure 4. Opponent cells in superior retina showed relatively balanced $M / S$ antagonism. $A$, Response waveforms (PSTHs, in blue) of an $S+/ M-$ opponent cell from superior retina in response to flashed monochromatic spots (diameter $\sim 850 \mu \mathrm{m}$; flash duration $300 \mathrm{~ms}$; flash onset at $100 \mathrm{~ms}$ in the plots). Sameformat as Figure 2 . The flash intensities were $3.99 \times 10^{4}, 5.68 \times 10^{4}, 3.23 \times 10^{4}$, and $2.40 \times 10^{5}$ quanta $/ \mu \mathrm{m}^{2} / \mathrm{s}(440,460,530$, and $610 \mathrm{~nm})$. The response amplitudes were measured from the fitted waveforms at either flash onset or offset, depending on the polarity of the response (see Appendix A). The background produced $4.11(\mathrm{M}), 4.06(\mathrm{~S})$, and 4.70 (Rod) $\log _{10} \mathrm{Rh}$ /photoreceptor/s. Data shown are from the first block of trials for this cell. $\boldsymbol{B}$ and $C$ also show data from this block of trials for the same cell and background intensity. The morphology of this cell is shown in the second panel from top in Figure 7 A. $B$, Flash contrast-response function. Response amplitudes of either ON (solid gray circles) or OFF (solid blue circles) responses to monochromatic flashes of wavelengths from 420 to $620 \mathrm{~nm}$ were fitted with two static nonlinearities (solid red line for ON responses; dashed red line for OFF responses) as described in Appendix B. The $x$-axis of the plot is the weighted input contrast, $C_{\text {input }}$, derived from the model fit (see Eq. B1 in Appendix B). $C$, Action spectrum of an $S+/ M-$ opponent cell in superior retina. The same data as in $\boldsymbol{B}$ are plotted as a spectral sensitivity. The solid and dashed red lines represent the magnitude of the weighted sum of $\mathrm{M}, \mathrm{S}$, and rod contrast sensitivities as determined by the model fit. The solid line represents the wavelength region where there was an $0 \mathrm{~N}$ response, while the dashed line represents the wavelength region where there was an $0 \mathrm{FF}$ response. The relative photopigment weights used to produce the action spectrum were $\mathrm{M}:-0.41, S: 0.58$, and rod: -0.02 and are shown by the horizontal bars in the inset (magnitudes of the $\mathrm{M}, \mathrm{S}$, and rod weights are represented by green, blue, and gray bars). Sensitivity dropped significantly between 460 and $480 \mathrm{~nm}$, indicating the spectral neutral point (see also Fig. 3). The overall shape of the action spectrum here and in $\boldsymbol{F}$ resembles the guinea pig increment-threshold spectral sensitivity measured behaviorally by Jacobs and Deegan (1994). The vertical location of the data points on the spectral plots has been corrected for variation in stimulus intensity across wavelength and for the shape of the cells' ON and OFF static nonlinearities (see Appendix B) (Yin et al., 2006). D, Response waveforms (PSTHs, in blue) of an M+/S - opponent cell from superior retina to flashed monochromatic spots (diameter $\sim 850 \mu \mathrm{m}$; flash duration $300 \mathrm{~ms})$. Same format and background intensity as $A$. The flash intensities were $3.42 \times 10^{4}, 5.08 \times 10^{4}, 2.96 \times 10^{4}$, and $2.12 \times 10^{5}$ quanta $/ \mu \mathrm{m}^{2} / \mathrm{s}(440,460,530$, and $610 \mathrm{~nm}$ ). Data shown are from the first block of trials for this cell. $\boldsymbol{E}$ and $\boldsymbol{F}$ also show data from this block of trials. The morphology of this cell is shown in the second panel from top in Figure 7B. $\boldsymbol{E}$, Flash contrast-response function. Same format as $\boldsymbol{B}$. F, Action spectrum of an $S+/ M-$ opponent cell from superior retina. Same format as $C$. The relative weights were M: $0.42, S:-0.51$, and rod: 0.07 and are shown in the inset. Because the response amplitude to the flash at $470 \mathrm{~nm}$ was zero, no data point is plotted for that wavelength. 

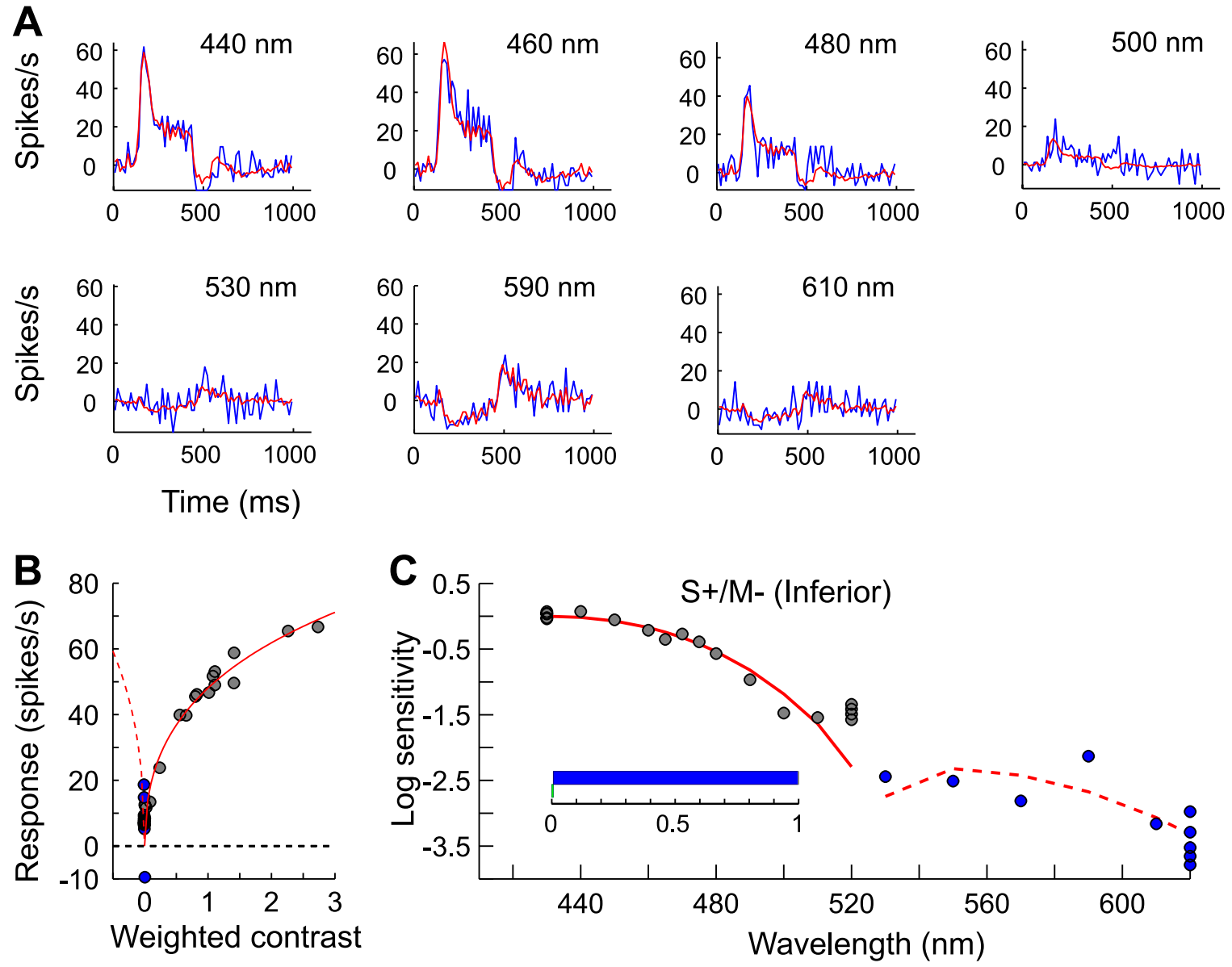

Figure 5. Opponent cells in inferior retina were dominated by $S$ input. $A$, Response waveforms (PSTHs, in blue) of an $S+/ M-$ opponent cell from inferior retina to flashed monochromatic spots (diameter of $\sim 800 \mu \mathrm{m}$; flash duration of $300 \mathrm{~ms}$ ). Same format and background intensity as Figure $4 A$. The flash intensities were $5.69 \times 10^{4}, 1.57 \times 10^{5}, 8.74 \times 10^{4}, 5.14 \times 10^{4}, 4.62 \times 10^{4}$, $1.66 \times 10^{5}$, and $3.74 \times 10^{5}$ quanta/ $\mu \mathrm{m}^{2} / \mathrm{s}(440,460,480,500,530,590$, and $610 \mathrm{~nm})$. Data shown are from the first block of trials for this cell. $B$ and $C$ also show data from this block of trials. The morphology of this cell is shown in the top panel of Figure $7 C$. $B$, Flash contrast-response function. Same format as Figure $4 B$. For one data point (one of four measurements made at $520 \mathrm{~nm}$ ) at low weight input contrast, the response polarity of the data differed from that of the model prediction. This point is shown in the plot as having a negative response value. Note that this sign reversal is of small magnitude and occurs near the spectral neutral point of the cell. $C$, Action spectrum of an $S+/ M-$ opponent cell from inferior retina. Same format as Figure $4 C$. The relative weights were $\mathrm{M}:-0.01, \mathrm{~S}: 0.99$, and rod: 0 and are shown in the inset. That data point indicated in $\boldsymbol{B}$ as having a negative response is not shown on this logarithmic plot.

(data not shown) of five more $\mathrm{S} / \mathrm{M}$ opponent cells in superior retina $(S+/ M-: n=3 ; M+/ S-: n=2)$. Four of these cells appeared to stratify in the $\mathrm{ON}$ stratum. A fifth appeared to stratify in the OFF stratum, based on staining of the primary and secondary dendrites. But the distal dendrites, which would provide more reliable information about the locus of dendritic stratification, were not stained and prevent us from attaching much significance to this observation.

Table 1 also provides the number of $S$ cones labeled within the dendritic field of opponent cells in superior retina, the density of S cones within the dendritic field, and estimates of the S-cone percentage within the dendritic field. The latter were obtained by assuming an overall cone density of 20,000 cones $/ \mathrm{mm}^{2}$ (Yin et al., 2006). The mean value for the S-cone percentage $(n=5)$ was $4.5 \%$, slightly smaller than previous estimates of $\sim 6 \% \mathrm{~S}$ cones in guinea pig superior retina (Röhlich et al., 1994; Yin et al., 2006). We regard the previous estimates as more reliable because they were obtained in a preparation where both $\mathrm{S}$ and $\mathrm{M}$ cones were labeled in the same retinal region, and thus not subject to error introduced by local variation in overall cone density.

In tangential view the dendritic pattern of opponent ganglion cells was similar to that of rabbit G9 cells, while their dendritic stratification resembled that of rabbit G10 cells (Rockhill et al., 2002). None of the known rabbit ganglion cells, however, have a morphology that corresponds completely to that of the opponent ganglion cells we studied.

The amount of information that a ganglion cell collects, and the area over which it does so, are key aspects of its function. Both are constrained by the number and distribution of its bipolar synapses. For all ganglion cell types studied to date synaptic density is constant at $\sim 19$ synapses per $100 \mu \mathrm{m}^{2}$ of dendritic membrane, independent of cell type (Xu et al., 2008). Therefore, measuring dendritic membrane area for the color-opponent cells provides an indirect estimate the number of bipolar synapses for comparison to other known types. For our cells, the total area of the dendritic membrane was $2.1 \pm 0.3(\mathrm{SD}) \times 10^{4} \mu \mathrm{m}^{2}$ (data available from seven of the eight cells in Fig. 7; see also supplemental Fig. 2, available at www.jneurosci.org as supplemental material). The average peak density of dendritic membrane area was $51 \mu \mathrm{m}^{2}$ per 100 $\mu \mathrm{m}^{2}$ retinal area. Thus assuming the same density and distribution of synapses as for other ganglion types, the coloropponent cell would collect about $\sim 3900$ synapses. This number is similar to those obtained for ON-OFF directionselective (DS) and local-edge detecting (LE) ganglion cells, but 
smaller than that for brisk-sustained (BS) ganglion cells and larger than that for brisk-transient (BT) ganglion cells (supplemental Fig. 2, available at www. jneurosci.org as supplemental material) (Xu et al., 2008).

\section{Some bistratified ganglion cells were nonopponent}

We stained a few cells that met the anatomical and physiological screening criteria but that were not opponent as revealed by the flickering spot protocol. Two of these were bistratified ganglion cells. Their morphologies are shown in Figure $8 A$, their physiological responses in Figure $8 B, C$. The morphology, including the depth of dendritic stratification, differs from that of other well-studied bistratified ganglion cells in guinea pig, such as the $\mathrm{ON}-\mathrm{OFF}$ direction-selective and $\mathrm{ON}-\mathrm{OFF}$ ganglion cells (data not shown). A ganglion cell type with similar dendritic stratification, the G3 bistratified ganglion cell, has been reported in rabbit [Rockhill et al. (2002), their Figs. 2, 4]. Indeed, Rockhill et al. (2002) speculated that this bistratified type might be color-opponent. If the bistratified cells we studied are the homolog of the G3, however, this is not the case. Moreover, the fact that the bistratified cells we identified are not opponent also makes it unlikely that they are the homolog of the small bistratified ganglion cell that has been well-studied in primate (Dacey, 1993; Dacey and Lee, 1994; Ghosh et al., 1997; Ghosh and Grünert, 1999; Silveira et al., 1999; Dacey and Packer, 2003; Dacey et al., 2005).

\section{Receptive field structure}

We collected area summation data of the sort shown in Figure $2 B$ for six $S+/ M-$ and six $\mathrm{M}+/ \mathrm{S}-$ opponent cells from superior retina and one $S+/ M-$ cell from inferior retina (see Fig. 9 and supplemental Fig. 1, available at www.jneurosci.org as supplemental material). These data can be used to infer receptive field properties of the cells, by fitting them with a Difference of Gaussians (DOG) receptive field model, as described in Appendix C. Briefly, we fit each cell with a Gaussian center and surround. Both the center and surround took a weighted sum of S and M inputs; the weights for both center and surround were parameters of the model. Because the area summation data were collected using the LCD system, we did not have direct measurements of the rod contribution at each stimulus size. In fitting the data, we assumed a constant rodcone coupling strength and fixed the value of this strength at the average value derived from measurements of spectral sensitivity (see Fig. 11 and Table 2). Derivation of this value is discussed below (Functional model; Appendix D). In addition, we used data from each cell collected at one spot size to constrain the static nonlinearity of that cell, as described in Appendix C.

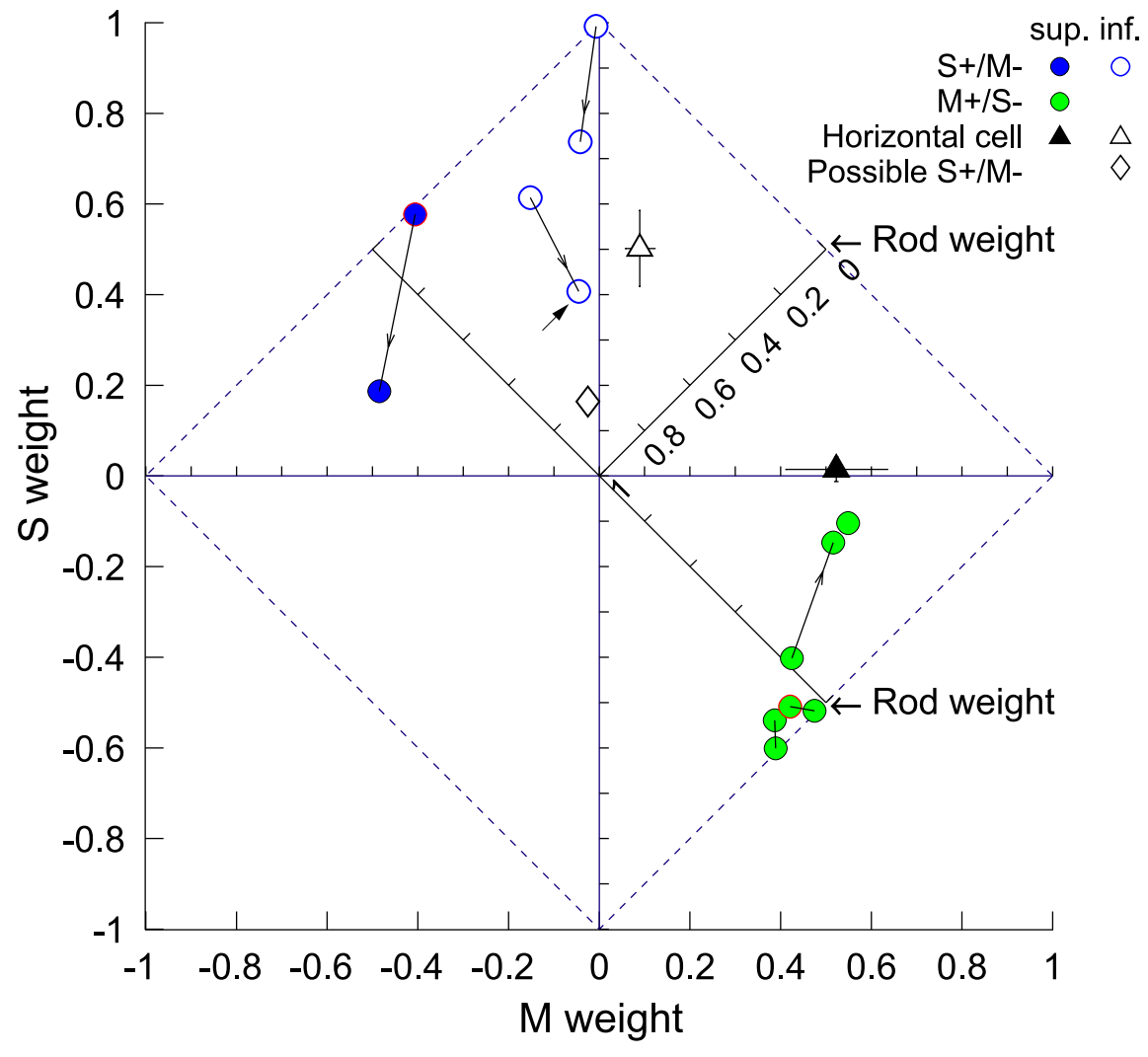

Figure 6. Photopigment weights of S/M opponent cells vary across retina and differ from those for horizontal cells and other types of ganglion cells. Photopigment weights of all ganglion cells measured in this study are shown. The $x$ - and $y$-axes indicate the relative $M$ and $S$ weights. The position of each point along a third axis, extending from the origin along are plotted as solid and open symbols respectively. Opponent cells are plotted as solid and open circles in the second and forth quadrants, with symbol colors of blue and green for $S+/ M-$ and $M+/ S-$ types. One possible $S+/ M-$ opponen

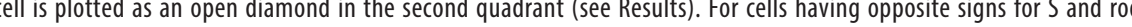
weights, the edge of the corresponding symbol is shown in red, otherwise in black. All measurements were made at simila (see Materials and Methods). For cells studied for multiple blocks of trials, photopigment weights a substantial shift in weights across blocks, the arrow on the connecting line points to the second block. Opponent cells in superior retina showed relatively balanced antagonism between $M$ and $S$ inputs, but in inferior retina $S$ input dominated. For comparison, the mean photopigment weights ( \pm SD) of horizontal cells in superior and inferior retina at a similar background intensity are plotted as solid and open triangles [Yin et al. (2006), their Fig. 3]. The photopigment weights of brisk-transient ganglion cells (see Fig. 11) are similar to those of horizontal cells (Yin et al., 2006).

Figure 9 shows area summation data along with the receptive field structure derived from the fits for six cells: two $\mathrm{S}+/ \mathrm{M}-$ opponent cells from superior retina (Fig. $9 A$ ), three $M+/ S-$ opponent cells from superior retina (Fig. $9 B$ ), and one $\mathrm{S}+/ \mathrm{M}-$ opponent cell from inferior retina (Fig. $9 C$ ). For these cells, we also had morphological data that allowed us to estimate dendritic field diameter. Supplemental Figure 1 (available at www.jneurosci. org as supplemental material) shows area summation data and receptive field structure for an additional seven cells (four $\mathrm{S}+/ \mathrm{M}-$ and three $\mathrm{M}+/ \mathrm{S}-$ opponent cells from superior retina). For the most part, the area summation curves were well fit by the model. The receptive field structure is plotted as the spatial profile of the S and M components; within the model each of these is a Difference of Gaussians. For 11 of the 13 cells, the receptive field structure had opposed S- and M-cone receptive fields, each with a dominant center Gaussian component. This is the classic type II receptive field structure (Wiesel and Hubel, 1966) exhibited by primate S-cone opponent cells (Dacey and Lee, 1994; Dacey, 1996; Dacey and Packer, 2003; Field et al., 2007). 
Table 1. Morphological and anatomical parameters for opponent ganglion cells

\begin{tabular}{|c|c|c|c|c|c|c|}
\hline & $\begin{array}{l}\text { Depth of } \\
\text { stratification (\%) }\end{array}$ & $\begin{array}{l}\text { Density of ON } \\
\text { dendritic processes }(1 / \mu \mathrm{m})\end{array}$ & $\begin{array}{l}\text { Dendritic field } \\
\text { diameter ( } \mu \mathrm{m})\end{array}$ & $\begin{array}{l}\text { No. of } S \text { cones within } \\
\text { dendritic field }\end{array}$ & $\begin{array}{l}\text { S-cone density within } \\
\text { dendritic field }\left(1 / \mathrm{mm}^{2}\right)\end{array}$ & $\begin{array}{l}\text { Estimated S-cone percentage } \\
\text { within dendritic field }\end{array}$ \\
\hline \multirow[t]{4}{*}{$S+/ M-$, superior } & 72 (mean) & 0.059 (mean) & 374 (mean) & 96 (mean) & 903 (mean) & $4.5 \%$ (mean) \\
\hline & $2.7(S D)$ & 0.005 (SD) & $35(S D)$ & $13(S D)$ & $30(S D)$ & $0.2 \%(S D)$ \\
\hline & $(n=2)$ & $(n=3)$ & $(n=3)$ & $(n=2)$ & $(n=2)$ & $(n=2)$ \\
\hline & 77 (mean) & 0.061 (mean) & 329 (mean) & & & \\
\hline \multirow{2}{*}{$\mathrm{S}+/ \mathrm{M}-$, inferior } & $2.5(S D)$ & $0.008(S D)$ & $12(S D)$ & & & \\
\hline & $(n=2)$ & $(n=2)$ & $(n=2)$ & & & \\
\hline \multirow{3}{*}{$M+/ S-$, superior } & 77 (mean) & 0.063 (mean) & 326 (mean) & 76 (mean) & 907 (mean) & $4.5 \%$ (mean) \\
\hline & $3.3(S D)$ & 0.007 (SD) & $44(S D)$ & $14(S D)$ & $165(S D)$ & $0.8 \%(S D)$ \\
\hline & $(n=3)$ & $(n=3)$ & $(n=3)$ & $(n=3)$ & $(n=3)$ & $(n=3)$ \\
\hline
\end{tabular}

There are two exceptions to the general characterization above. (1) For one $\mathrm{S}+/ \mathrm{M}-$ cell from superior retina (supplemental Fig. $1 A$, second panel from the top, available at www. jneurosci.org as supplemental material), the $\mathrm{M}$-cone receptive field showed more marked spatial antagonism than for the other cells. Correspondingly, the area summation data showed that this cell's responses had a nonopponent character for small spot sizes. The $\mathrm{S}+/ \mathrm{M}-$ opponency emerges in the area summation data only for large spot sizes. (2) The $\mathrm{S}+/ \mathrm{M}-$ cell from inferior retina does not appear opponent in fits or in the area summation data (Fig. 9C). We attribute this to drift in the rod input to the cell over time. The area summation data were collected after the monochromatic flash data presented in Figure 3 ( $\mathrm{S}+/ \mathrm{M}-$ opponent cell, index 1). As shown in Figure 3, the second block for this cell did not reveal a spectral neutral point, and the cell had a large estimated rod weight for this block (Fig. 6, arrow). If we refit the area summation data for this cell assuming a rod-cone coupling constant consistent with this larger rod weight, the derived M receptive field component is very weakly antagonistic to the derived S component (fit not shown).

We quantified the spatial extent of the S- and M-cone components of the receptive fields for the 11 cells that showed type II receptive fields (that is, for all cells except the two noted in the previous paragraph) by finding the diameter that accounted for $80 \%$ of the unsigned volume of each components' receptive field. These diameters are indicated for each cell by horizontal blue and green bars (Fig. 9; supplemental Fig. 1, left panels, available at www.jneurosci.org as supplemental material). Figure 10 shows a scatterplot of the $\mathrm{M}$-cone component diameters versus S-cone component diameters. The spatial extents of the M-cone component of the receptive fields were slightly larger than those of the $\mathrm{S}$-cone components. A similar observation has been reported for primate S-cone opponent cells (Dacey, 2000; Field et al., 2007). For cells where we had morphological data, we also plot the dendritic field diameter (Fig. 9, gray bars in left panels). Dendritic field diameters are smaller than the physiologically characterized diameters, although clearly the exact relation depends on the criterion used to define the physiological diameters. In dichromatic mammals and primates, S-ON cone bipolar cells have long and meandering dendrites and axons (Mariani, 1984; Kouyama and Marshak, 1992; Haverkamp et al., 2005; MacNeil and Gaul, 2008), which could provide a mechanism for opponent ganglion cells to collect input from $S$ cones located in regions adjacent to their dendritic fields. The relationship in the relative size between physiologically measured receptive field and anatomically measured dendritic field that we observed is roughly consistent with that found for other ganglion cell types, such as brisk-transient ganglion cells (Borghuis et al., 2008).

\section{Functional model}

In the context of the evolution of color vision, it is of interest to know whether a change in cone opsin expression can enhance visual performance in the absence of a concomitant change in postreceptoral circuitry (Jacobs et al., 2007; Mancuso et al., 2007). We thus asked, can the differences in cone weights across the superior-inferior opsin gradient, both for the opponent cells reported here and for achromatic cells (Yin et al., 2006), be explained by assuming common postreceptoral circuitry in superior and inferior retina? To address this, we constructed a functional model that predicts the strength of photopigment inputs to each class of cells studied. In outline, the model is characterized by the following parameters: (1) the proportion of $S$ cones in superior retina, which is also the proportion of genuine S cones (Haverkamp et al., 2005) in inferior retina, (2) the relative gain of S-cone signal conveyed to the S/M opponent ganglion cells, (3) the strength of rod coupling to cones, which is assumed to be indiscriminate across all cones (Ahnelt et al., 1990), and (4) the proportion of $M$ pigment coexpressed in nongenuine $S$ cones in inferior retina. Appendix D describes the relation between these parameters and predicted photopigment weights. We used a numerical search procedure to find the parameter values that best predicted the measured weights. The model also incorporates two additional assumptions, which we think are reasonable. These are: (1) rod signals reach ganglion cells only through rod-cone gap junctions at the light intensities of our study (Sharpe and Stockman, 1999; Bloomfield and Dacheux, 2001; Sterling, 2004), and (2) M- and S-opsins drive the phototransduction cascade with equal gain, independent of the cone type in which they are expressed (Nikonov et al., 2006).

The modeling results are provided in Table 1, and the corresponding predictions are plotted with the data in Figure 11. The predicted weights capture all of the broad features of the measurements and are in reasonable quantitative agreement. Given the simplicity of the model, we take this agreement as indicating that the model provides a plausible account of the physiology. The key conclusion is that a single change in opsin expression pattern across the retina, without any other change in circuitry, is consistent with all of the observations reported here and in our previous study.

\section{Discussion}

\section{Properties of S/M opponent cells in guinea pig}

Our study is the first to jointly characterize the physiology and morphology of S/M opponent cells in a nonprimate mammalian species. In guinea pig superior retina, we find that S/M oppo- 
A S+/M- (Superior)
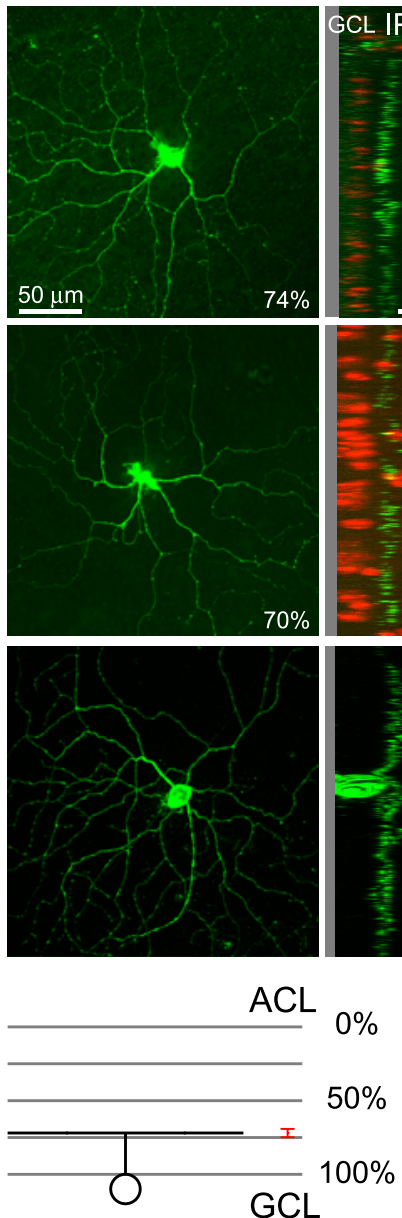

B $\mathrm{M}+/ \mathrm{S}$ - (Superior)

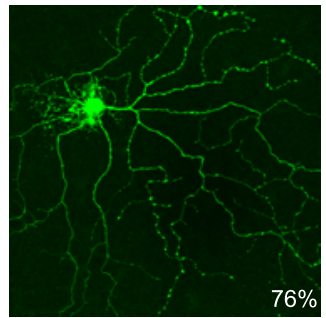

$76 \%$
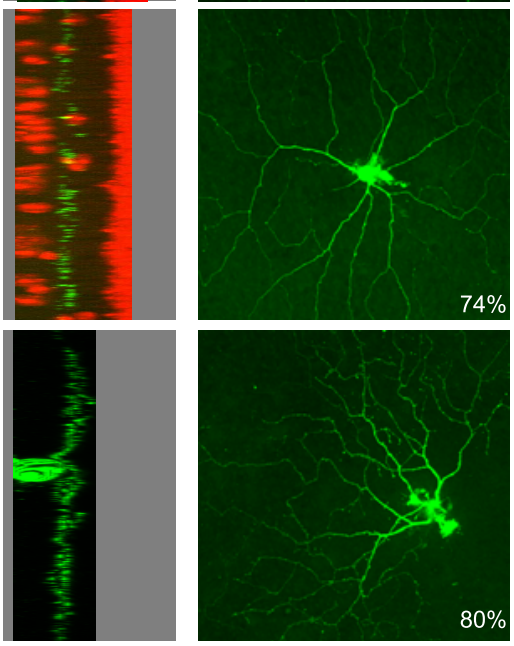

$80 \%$

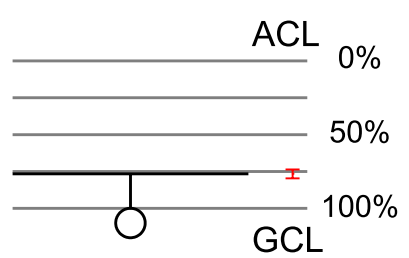

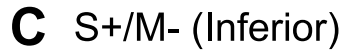
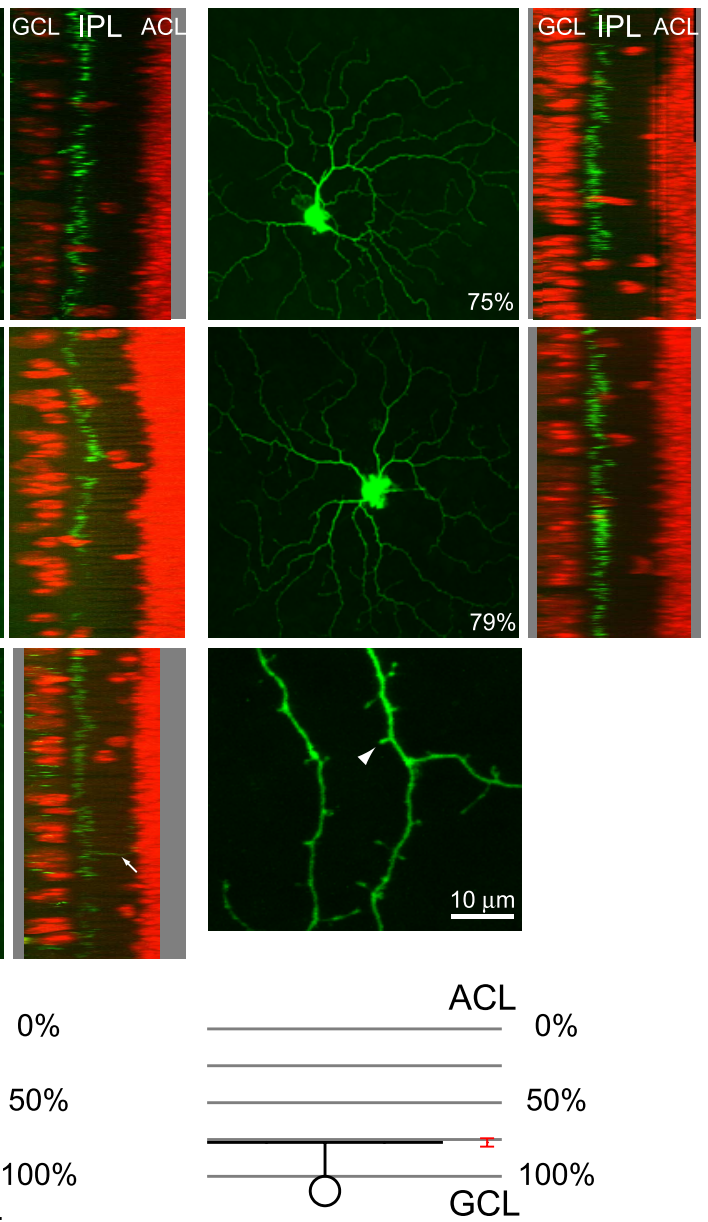

Figure 7. Dendrites of S/M opponent cells were located in the IPL's ON stratum. $\boldsymbol{A}-\boldsymbol{C}$, Top panels, Tangential and radial views of all well stained opponent cells. In the radial view, the IPL is the region between the GCL and $A C L$ (bands of red staining on the left and right). In the figure, the horizontal dimension of each radial view is stretched by $300 \%$ relative to the vertical dimension. Based on the staining pattern (upper and middle panels) or the distance between the dendritic layer of a cell (bottom panel) to the right edge of its soma ( $\sim 3 \mu \mathrm{m}$ ), all cells stratified close to the $\mathrm{GCL}$, that is in the $0 \mathrm{~N}$ stratum. If available, the depths of dendritic stratification are labeled on the tangential views (bottom-right corners) and also visualized in the bottom. For one $M+/ S$ - opponent cell (the third panel from top in $\boldsymbol{B}$ ), a small proportion of dendrites looped into the 0 FF stratum (at a depth of $15 \%$; tangential view, arrow), then terminated back into the $0 \mathrm{~N}$ stratum ( $10 \%$ of the total length of the $0 \mathrm{~N}$ dendrites; data not shown). $\mathrm{S}+/ \mathrm{M}-$ opponent cells in inferior retina had many very short lateral branches in their dendrites (one example shown as arrowhead in the third panel from top in $\boldsymbol{C}$, which was enlarged from the panel above). We tested seven of the eight cells for opponency using both flickering spots and flashed monochromatic spots (see also Figs. 2C, 3, and 4A, D and 5A), and further estimated the photopigment weights of six cells from their flash data (see Figs. $4 C, F$ and $5($ and 6 ). One $S+/ M-$ opponent cell (the third panel from top in $A$ ) was encountered during a different experiment and was only tested for opponency using flickering spots (see Materials and Methods). For another $S+/ M-$ opponent cell (top panel in $\boldsymbol{A}$ ) we did not have sufficient data from the flash experiments to allow quantitative estimation of photopigment weights. $\boldsymbol{A}-\boldsymbol{C}$, Bottom panels, Summary of dendritic stratification for opponent cells. The means of the depth of dendritic stratification were similar across opponent types and retinal locations $(\boldsymbol{A}, 72 \% ; \boldsymbol{B}, 77 \%$; and $\boldsymbol{C}, 77 \%)$. Error bars in red show the SD.

nency is conveyed by both $\mathrm{S}+/ \mathrm{M}-$ and $\mathrm{M}+/ \mathrm{S}-$ opponent cells, consistent with earlier physiological reports for ground squirrel, cat, rabbit, mouse, and guinea pig (Michael, 1966; Cleland and Levick, 1974; Caldwell and Daw, 1978; Jacobs et al., 1981; Ekesten et al., 2000; Hemmi et al., 2002; Grivich et al., 2005). Both opponent cell types share similar morphology, with a flat dendritic arbor that stratifies in the IPL's ON stratum. Both types also have similar chromatic properties, in that $\mathrm{S}$ and $\mathrm{M}$ photopigment weights are approximately balanced. $\mathrm{S}+/ \mathrm{M}-$ and $\mathrm{M}+/ \mathrm{S}-$ cells in superior retina have type II receptive fields: the S and $\mathrm{M}$ components of the receptive field are of approximately equal size, with the $\mathrm{M}$ component being slightly larger for both $\mathrm{S}+/ \mathrm{M}-$ and $\mathrm{M}+/ \mathrm{S}-$ types.

In inferior retina, we found two $\mathrm{S}+/ \mathrm{M}-$ cells and one $\mathrm{M}+/ \mathrm{S}-$ cell. The opponency of the $\mathrm{S}+/ \mathrm{M}-$ cells was weak, with the $\mathrm{S}$ input dominating the $\mathrm{M}$ input. We were not able to obtain sufficient physiological data on the $\mathrm{M}+/ \mathrm{S}-$ cell to characterize the strength of its opponency.

\section{Proportion of S/M opponent cells}

In all, we tested $>1679$ cells in superior retina for opponency in stages $1-4$. Of these, 16 were opponent. Taking the number of cells measured at the lower bound of 1679 , an upper bound on the observed proportion of opponent cells is 1\%. The 99\% Bayesian confidence interval (Lee, 1989) on this proportion, computed using an uninformative uniform prior, is $0.4 \%$ to $1.7 \%$. This proportion and confidence interval are exclusive of brisk transient cells and, for many of the measurements, of cells that did not meet the screening criteria.

Borghuis et al. (2008) show that in guinea pig, as in many other mammals (review by Wassle, 2004), the coverage factor for ganglion cells, defined as the product of dendritic field area 

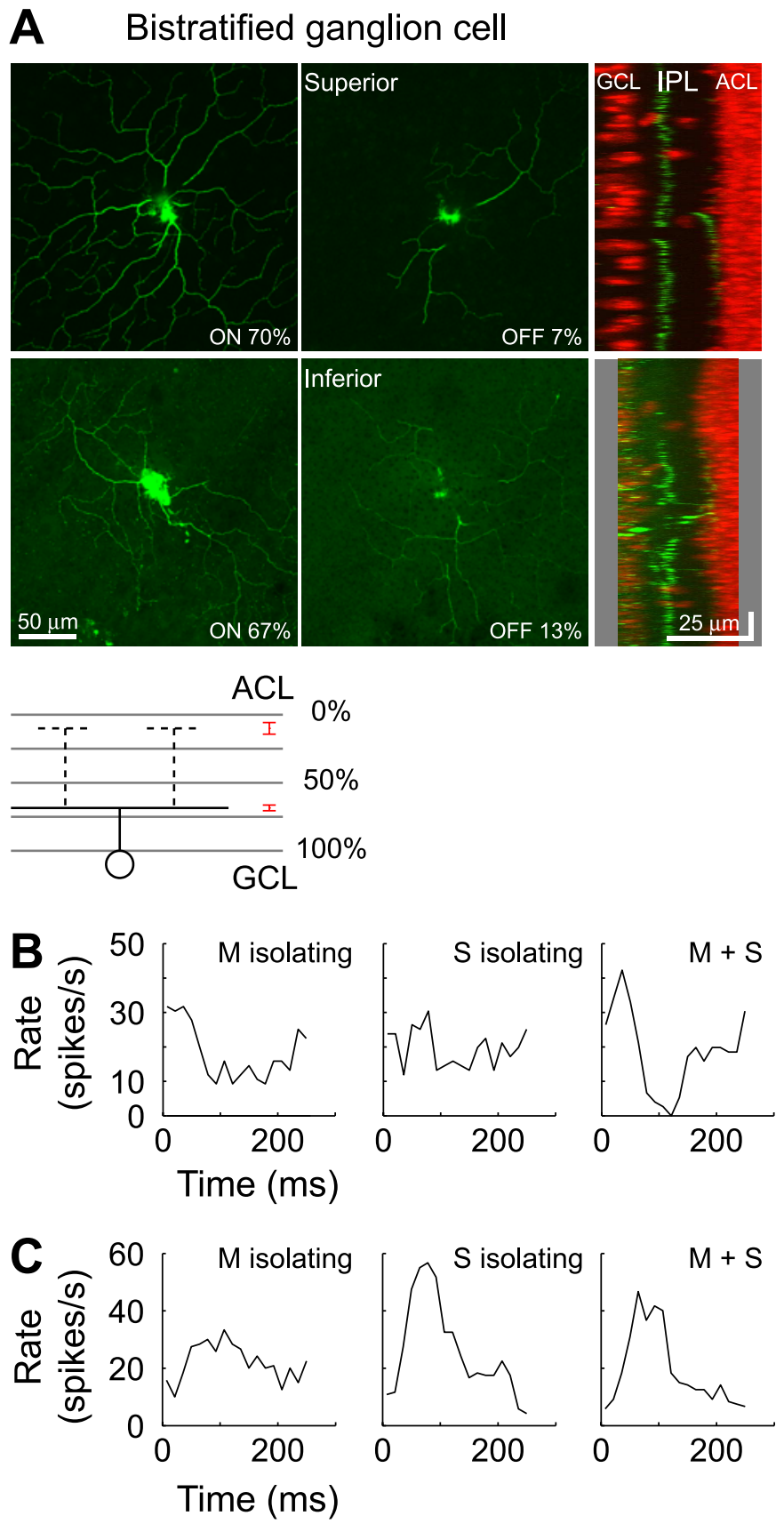

Figure 8. Bistratified ganglion cells did not show explicit opponency. A, Bottom panels, Tangential views of bistratified nonopponent ganglion cells that met both the anatomical and physiological screening criteria. For each cell, tangential views for ON and OFF dendrites as well as a radial are shown from left to right along each row. Top panels show a cell from superior retina and bottom panels show a cell from inferior retina. In the radial views, the IPL is the region between the $\mathrm{GCL}$ and $\mathrm{ACL}$ (bands of red staining on the left and right). The total length of the OFF dendrites was $23 \%$ of the total length of the $0 \mathrm{~N}$ dendrites for the cell from superior retina. The corresponding number for the cell from inferior retina was $78 \%$. $\boldsymbol{A}$, Bottom, Summary of dendritic stratification for the bistratified ganglion cells. Error bars in red show the SD for each stratum. $\boldsymbol{B}, \boldsymbol{C}$, Responses to flickering spots (PSTHs, dark lines) of the two bistratified ganglion cells shown in $\boldsymbol{A}$ and $\boldsymbol{B}$. Neither cell showed opponency. In $\boldsymbol{B}$, the stimulus diameter was $600 \mu \mathrm{m}$ and the stimulus was flickered at a temporal frequency of $4 \mathrm{~Hz}$. Modulation directions shown in the plots from left to right were $M$-cone isolating, $\mathrm{S}$-cone isolating, $\mathrm{M}+\mathrm{S}$ and $\mathrm{M}-\mathrm{S}$. The $\mathrm{M}$ and $\mathrm{S}$ cone contrasts, $\left[C_{M}, C_{S}\right.$, were (from left to right): [20\%,0\%], [0\%, 20\%], [20\%,20\%] and [20\%, - 20\%]. In C, the stimulus diameter was 800 $\mu \mathrm{m}$ and the stimulus was flickered at a temporal frequency of $4 \mathrm{~Hz}$. The $\mathrm{M}$ and $\mathrm{S}$ cone contrasts, $\left[\mathrm{C}_{\mathrm{M}}, \mathrm{C}_{\mathrm{S}}\right]$, were (from left to right): $[30 \%$, $0 \%],[0 \%, 30 \%],[21 \%, 21 \%]$ and $[21 \%,-21 \%]$. In $\boldsymbol{B}$, the response to $\mathrm{M}$-cone isolating modulation was stronger than that to $S$-cone isolating modulation, vice versa for $\boldsymbol{C}$. In both $\boldsymbol{B}$ and $\boldsymbol{C}$, responses to modulation along the $\mathrm{M}+\mathrm{S}$ nonopponent direction were stronger than those along the $\mathrm{M}$-S opponent direction.

and cell density, is roughly constant (between 3 and 4 ) for cell types in which dendritic tips extend to the neighboring soma. For these cell types, the coverage factor is independent of cell size and eccentricity. The mean dendritic field diameter for the
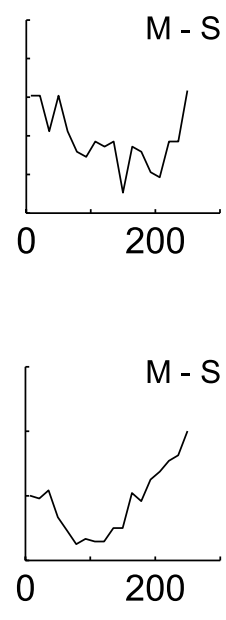

opponent cells was $344 \pm 39$ (SD) $\mu \mathrm{m}$ $(n=8)$. If we assume a coverage factor of 3.5 , we obtain a density estimate for each of the $S+/ M-$ and $M+/ S-$ types of $\sim 40$ cells $/ \mathrm{mm}^{2}$. Given the total density for all ganglion cells of $\sim 1500$ cells $/ \mathrm{mm}^{2}$ ( similar to Do-Nascimento et al., 1991; Kao and Sterling, 2006), the S+M- and $\mathrm{M}+/ \mathrm{S}-$ types would each represent $\sim 2-3 \%$ of the ganglion cell population. This is higher than the $\sim 1 \%$ proportion we observed in superior retina for the two types combined. Either our screening procedure missed some opponent cells or the coverage factor for the opponent cells is lower than for other cell types.

In inferior retina, 3 of 1407 cells that met our screening criteria showed opponency, for a proportion of $0.2 \%$ ( $99 \%$ confidence interval $0 \%$ to $0.7 \%$ ). The lower hit rate in inferior retina could reflect that fact that $\mathrm{S} / \mathrm{M}$ opponency there is weak. In particular, cells with stronger than average rod input might not show overt opponency when screened. None of the opponent cells in inferior retina had balanced $S$ and $\mathrm{M}$ photopigment weights. If there are strongly opponent cells in inferior retina that meet the screening criteria, they are very rare.

Ekesten and Gouras (2005) reported that $2 \%$ of ganglion cells they studied (physiology only) in mouse retina were opponent, somewhat higher than in our study. Given differences in species and sampling methods, however, it seems plausible that our data are tapping the same population of opponent cells they sampled. An earlier study from the same group (Ekesten et al., 2000) reported a higher percentage of S/M opponent cells in both superior and inferior retina in mouse.

\section{Relation to melanopsin-expressing ganglion cells}

In primate, "giant" monostratified melanopsin-expressing ganglion cells are color opponent (Dacey et al., 2005). Although we did not explicitly investigate whether the S/M opponent cells we studied express melanopsin, we think it is unlikely that they do. First, the spectral sensitivity of melanopsin peaks at around 480 $\mathrm{nm}$ (Berson et al., 2002; Dacey et al., 2005). However, as shown in Figure 3, the spectral neutral point of the S/M opponent cells in superior retina is at around that wavelength. On this point, we acknowledge that our procedures would not maximize the contribution of the sluggish temporal response characteristic of melanopsin (Berson et al., 2002; Dacey et al., 2005). Second, melanopsin-expressing ganglion cells are 
known to encode absolute irradiance (Dacey et al., 2005). However, for 11 S/M opponent cells, we measured maintained rates in both light and dark. These were similar (average of 29 and 24 spikes/s, respectively). Third, Dacey et al. (2005) report that the "giant" melanopsinexpressing ganglion cells were $(\mathrm{L}+\mathrm{M})+$ / $\mathrm{S}-$. Here we report both $\mathrm{M}+/ \mathrm{S}-$ and $\mathrm{S}+/ \mathrm{M}-$ types, with similar dendritic stratifications.

\section{Implications for retinal circuitry}

Our data constrain the circuit configurations for $\mathrm{S}+/ \mathrm{M}-$ and $\mathrm{M}+/ \mathrm{S}-$ ganglion opponent cells. First, the excitatory signals should flow through ON bipolar cells. Second, in superior retina at least, the circuit should allow selective amplification of signals from $S$ cones to produce the observed balanced opponency. Finally, the circuitry should account for the fact that the S- and $\mathrm{M}$-cone components of the receptive field have approximately the same diameter.

The $\mathrm{S}+/ \mathrm{M}-$ cells probably receive their input from S-ON bipolar cells, whose existence in mammals is well-established (Mariani, 1984; Kouyama and Marshak, 1992; Calkins et al., 1998; Herr et al., 2003; Schein et al., 2004; Haverkamp et al., 2005; Li and DeVries, 2006; MacNeil and Gaul, 2008). The $\mathrm{M}$-antagonism might arise at the outer retina, as has been suggested for primate (Dacey et al., 1996; Dacey, 2000; Field et al., 2007; Packer et al., 2007; Davenport et al., 2008), and/or from amacrine inhibition driven by an $\mathrm{M}-\mathrm{ON}$ bipolar cell ( $\mathrm{Li}$ and DeVries, 2006). In either case, the S-ON bipolar cells could selectively amplify the signals from $\mathrm{S}$ cones.

For the $\mathrm{M}+/ \mathrm{S}-$ cells, the excitatory $\mathrm{M}$ input could arise directly from an M-ON bipolar cell (Li and DeVries, 2006). In this case, the most likely source of the amplified inhibitory $S$ input would be through an amacrine cell that connected to the $\mathrm{S}-\mathrm{ON}$ bipolar cell. Alternately, if the S-ON bipolar cell itself carries antagonistic $M$ signals, the $M+/ S-$ opponent cell could simply receive the majority of its input from the S-ON bipolar cell through a sign-inverting amacrine cell. This latter possibility would make the S opponent circuit similar to that of the mammalian rod bipolar pathway, where a single type of rod ON bipolar cell drives both $\mathrm{ON}$ and OFF ganglion cells (Sterling, 1983; Müller et al., 1988; Bloomfield and Dacheux, 2001). Similar possibilities have been suggested for the inhibitory $\mathrm{S}$ input to $\mathrm{M} / \mathrm{L}-\mathrm{ON}$ :S-OFF ganglion cells in primate (Dacey and Packer, 2003).

\section{Weak color vision in guinea pig inferior retina?}

Our results indicate that $\mathrm{S} / \mathrm{M}$ opponency is considerably weaker in inferior retina than in superior retina. As color vision is generally conceived as depending on antagonistic processing of signals from different cone types, the weak opponency of identified $\mathrm{S} / \mathrm{M}$ opponent cells in inferior retina suggests that color vision may in turn be weak or nonexistent in inferior retina. Note that behavioral measurements of guinea pig color vision (Jacobs and Deegan, 1994) did not control the retinal location of the stimuli, and that the spectral sensitivities revealed by those measurements are similar to the spectral properties of S/M opponent cells in superior retina.
Functional significance of the dual gradient in cone opsin expression

We speculate that the dual gradient is an adaptation that sacrificed color vision in inferior retina, presumably in favor of improved performance for some other aspect of vision. The improvement might be in achromatic contrast detection against the blue sky, the background typically seen by inferior retina (Szél et al., 2000; Osorio and Vorobyev, 2005; Peichl, 2005; Yin et al., 2006). Such an adaptation could be quite important for a species such as guinea pig, which forages in low grass and is under strong pressure from avian predators (Cassini, 1991; Cassini and Galante, 1992; Asher et al., 2004). Previously we showed that the dual gradient in cone opsin expression is preserved in the physiology of the brisk-transient ganglion cells, which are thought to mediate achromatic contrast detection. That result plus our current data strengthens the speculation that the dual gradient is an adaptation to maximize contrast sensitivity in inferior retina.

\section{Appendix A: measuring response amplitudes with template fitting}

This appendix describes the template fitting method used to characterize the response amplitudes from the PSTHs of a ganglion cell.

\section{Rationale for the template fitting method}

We assumed that the individual PSTHs of a ganglion cell could be divided into one of two groups according to their $\mathrm{ON}$ or OFF response polarities, and that all the PSTHs within a group shared a common temporal response waveform that differed only in overall response amplitude and baseline rate. Under these assumptions, we could form a temporal response waveform template for each group by combining data from the PSTHs within that group. We fit each individual PSTH with a scaled and shifted version of the response template. This allowed us to obtain a more reliable estimate of response amplitude to each stimulus than if we had analyzed the PSTH for each stimulus independently.

\section{Forming the response template}

Each ganglion cell had its own templates. We first determined whether the PSTHs obtained from of a ganglion cell (all blocks of trials) showed both ON and OFF responses, or whether there was only a single group of responses. This was done by eye. If we could 

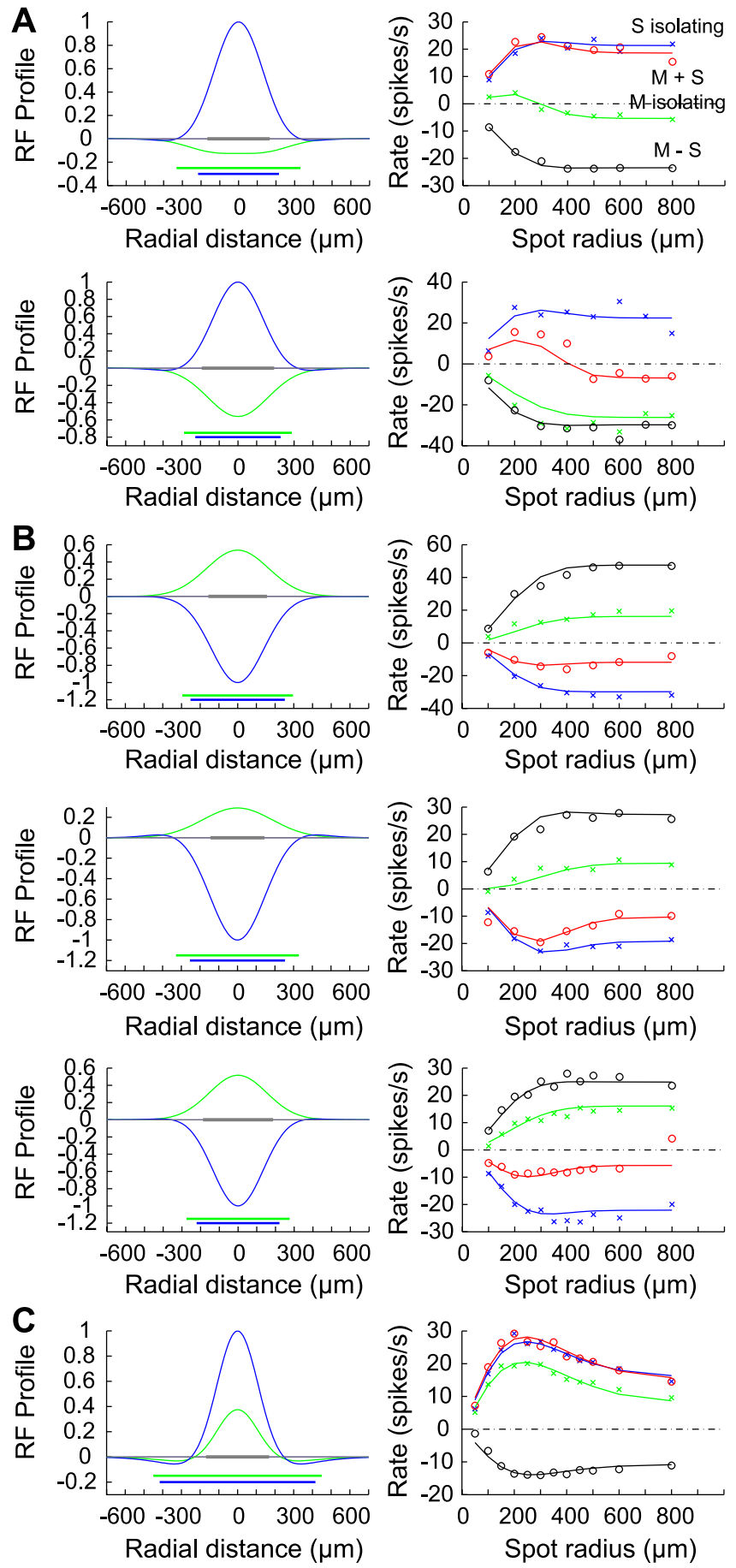

Figure 9. S- and M-cone receptive field components derived from DOG model. $\boldsymbol{A}-\boldsymbol{C}$, Left panels, One dimensional view of $S$ and $M$ receptive field components (RF profiles; blue for $S$ and green for M), normalized by the peak strength of the dominant input type (S or M). Actual RF profiles are circularly symmetric two-dimensional functions. The RF profiles were derived from the area summation data shown in the right panels (see Appendix $C$ ). In $\boldsymbol{A}, \boldsymbol{B}$, and $\boldsymbol{C}$, RF profiles for $S+/ M-$ opponent cells from superior retina, $M+/ S-$ opponent cells from superior retina and an $\mathrm{S}+/ \mathrm{M}-$ opponent cell from inferior retina are shown respectively. (Data and fits for additional S/M opponent cells from superior retina are shown in supplemental Fig. 1, available at www.jneurosci.org as supplemental material.) The spatial extents of the $S$ and $M$ receptive field components are indicated by the horizontal blue and green bars. These extents were calculated as the radius of the circular region that contained $80 \%$ of the unsigned volume of each component, where we defined the unsigned volume as the integral of the absolute value of the two-dimensional RF profile. The dendritic field diameter for each cell is shown as a gray horizontal bar. From the top to bottom, the cells in each panel of this figure correspond to those shown in Figure 7 in the following order: the second and the first panels from top in $A$, the second, the third and the first panels from top in $\boldsymbol{B}$, and the second panel from top in $\boldsymbol{C}$. $\boldsymbol{A}-\boldsymbol{C}$,

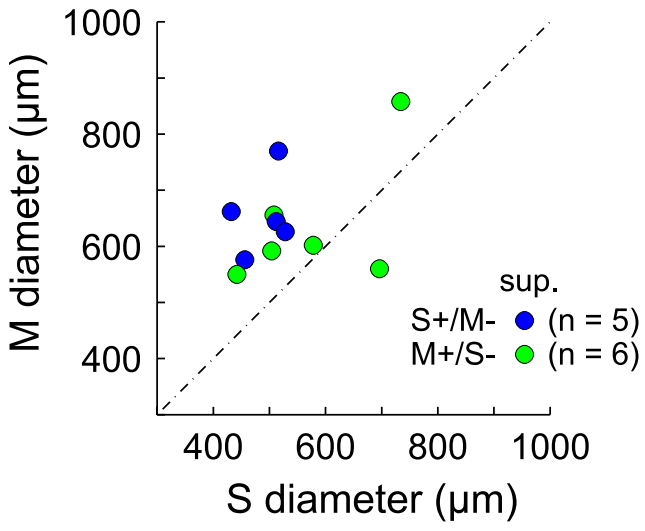

Figure 10. Comparison of $M$ and $S$ receptive field components. Scatter-plot of the spatial extents of $M$ versus $S$ receptive field components. $S+/ M-$ and $M+/ S-$ opponent cells are plotted in blue and green respectively for 11 opponent cells, all from superior retina. Two of the cells shown in Figure 9 and supplemental Figure 1 (available at www.jneurosci.org as supplemental material) are excluded from this plot, as noted in the text. The values of spatial extents plotted are the lengths of the blue and green horizontal bars for the corresponding cells in the left panels of Figure 9 and supplemental Figure 1, available at www.jneurosci.org as supplemental material. The average ratio of the spatial extents of $M$ to $S$ receptive field component for all 11 cells was 1.22 , significantly $>1$ (two-tailed $t$ test, $p<0.01$ ). In superior retina, this ratio was slightly larger for $\mathrm{S}+/ \mathrm{M}-$ (average ratio 1.35) than for $\mathrm{M}+/ \mathrm{S}-$ cells (average ratio 1.12). This difference was marginally significant (two-tailed $t$ test, $p<0.10$ ).

identify one or more PSTHs of clear ON polarity and one or more PSTHs of clear OFF polarity, we assumed there were two groups and formed two response templates for the cell, one $\mathrm{ON}$ and one OFF. Otherwise, we formed only one response template. For the $\mathrm{S} / \mathrm{M}$ opponent cells we studied, we found that the OFF template was not a sign-inverted version of the $\mathrm{ON}$ template.

To form the ON or OFF response template for a ganglion cell, we started by manually selecting PSTHs that (1) had clearly ON or OFF response polarities and (2) rectified mildly or not at all. That is, we tried to avoid using PSTHs where the spike rate dropped near zero for any substantial period. We then formed the response template as the weighted sum of the selected PSTHs. Each PSTH was weighted by the corresponding number of stimulus cycles that it contained. For convenience in later calculations, we normalized the template response by its maximum value. For many ganglion cells, it was not possible to avoid including some PSTHs that showed rectification.

\section{Fitting a response template and estimating response}

For opponent cells, we fit each individual PSTH with the ON template, the OFF template, and with a baseline template. For nonopponent cells, only a single ON or OFF template plus the baseline template was used. Template fitting for $\mathrm{ON}$ and $\mathrm{OFF}$ templates was accomplished by scaling and shifting, followed by clipping of any negative predicted rates to zero. The scale factor was constrained so that the peak rate was at least 1 spike/s. Baseline template fitting was accomplished by choosing a single positive baseline rate. To obtain the best fit, we minimized root mean squared error between predicted and

$\leftarrow$

Right panels, Area summation data with DOG receptive field model fits. Plots in the same format as Figure $2 B$. The data from Figure $2 B$ are replotted in the second panel from the top in $A$. The signed response amplitudes (F1) to modulations in four color directions are shown as green and blue crosses (for M- or S-cone isolating directions respectively) and red and green dots (for $\mathrm{M}+\mathrm{S}$ and $\mathrm{M}-\mathrm{S}$ color directions, respectively). The DOG model fits are plotted in the same color as the corresponding data points. 
measured PSTH time bins, excluding times when the template shape was not reliably determined because of rectification in the PSTHs used to form it.

After fitting the ON, OFF, and baseline templates we then choose the best fitting template based on the overall fit to the PSTH. For this comparison, no time bins were excluded in computing the error. A PSTH that was best fit with the ON template was considered an $\mathrm{ON}$ response, and its magnitude was taken as the positive peak of the fitted ON template's onset response (Figs. $2 C, 4 A, D, 5 A$ ). A PSTH that was best fit with the OFF template was considered an OFF response, and its response magnitude was taken as the positive peak of the fitted OFF template's offset response (Fig. $2 C, 4 A, D, 5 A$ ). A PSTH that was best fit with the baseline rate template was considered to have zero response. We denote the response estimated through this process at each wavelength as $R_{\mathrm{PSTH}}(\lambda)$. Response amplitudes were either positive or zero, and classified as $\mathrm{ON}$ or OFF.

\section{Iterating the fitting procedure}

The procedure described above could be sensitive to the PSTHs initially selected to form the response templates. To minimize this sensitivity, we iterated the procedure as follows. For each template (ON or OFF), we fit all the cell's PSTHs as described above and classified each PSTH as ON or OFF based on the fit. We then used the fits to the PSTHs to reselect those used to form each template, based on examination of the quality of the fit of each template to each PSTH and the polarity of the best fit template. In addition, we excluded PSTHs that were rectified in time bins inconsistent with the prediction from the best fitting template. This selection-template formation-check loop was iterated until we were satisfied that the resulting templates had stabilized.

\section{Appendix B: estimating action spectra from flash data for ganglion cells}

This appendix describes how we estimate action spectra and in turn the photopigment weights of a ganglion cell. The procedures are similar to those we used in Yin et al. (2006) to analyze spectral data obtained from horizontal cells. The modifications allow us to handle responses of opponent cells.

\section{Linear-nonlinear model}

As ganglion cells had response nonlinearities, we could not convert responses to action spectra directly by dividing the measured response amplitude at each wavelength $\lambda$ by the flash intensity $I(\lambda)$ at that wavelength. We used an LNL model to correct for response nonlinearities (Chichilnisky, 2001; Chatterjee and Callaway, 2002; Chichilnisky and Kalmar, 2002; Zaghloul et al., 2003).

The LNL model describes the responses of a ganglion cell as the result of passing an input contrast $C_{\text {input }}(\lambda)$ through a nonlinear contrast-response function. The input contrast was taken as the weighted sum of the contrasts $C_{\mathrm{M}}(\lambda), C_{\mathrm{S}}(\lambda)$, and $C_{\mathrm{Rod}}(\lambda)$ seen by $M$ cones, $S$ cones, and rods in response to the flash at wavelength $\lambda$ :

$$
C_{\text {input }}(\lambda)=w_{\mathrm{M}}^{\mathrm{c}} C_{\mathrm{M}}(\lambda)+w_{\mathrm{S}}^{\mathrm{c}} C_{\mathrm{S}}(\lambda)+w_{\text {Rod }}^{\mathrm{c}} C_{\mathrm{Rod}}(\lambda) .
$$

Here, $w_{\mathrm{M}}^{\mathrm{c}}, w_{\mathrm{S}}^{\mathrm{c}}$, and $w_{\mathrm{Rod}}^{\mathrm{c}}$ are the $\mathrm{M}, \mathrm{S}$, and rod weights and the sum of their absolute values is constrained to unity, $\left|w_{\mathrm{M}}^{\mathrm{c}}\right|+\left|w_{\mathrm{S}}^{\mathrm{c}}\right|+\left|w_{\text {Rod }}^{\mathrm{c}}\right|=$ 1 . The values of $C_{\mathrm{M}}(\lambda), C_{\mathrm{S}}(\lambda)$, and $C_{\mathrm{Rod}}(\lambda)$ are calculated from the spectral sensitivities of the photoreceptors $S_{\mathrm{M}}^{\mathrm{i}}(\lambda), S_{\mathrm{S}}^{\mathrm{i}}(\lambda)$, and $S_{\operatorname{Rod}}^{\mathrm{i}}(\lambda)$, the flash intensity $I(\lambda)$, and the isomerization rates seen by each receptor class to the background $\mathrm{Rh}_{\mathrm{M}, \mathrm{bg}}$, $\mathrm{Rh}_{\mathrm{S} \text {, bg }}^{*}$ and $\mathrm{Rh}_{\mathrm{Rod}, \mathrm{bg}}^{*}$ (Yin et al., 2006). Spectral sensitivities were those derived in the study by Yin et al. (2006) (see also Jacobs and Deegan, 1994; Govardovskii et al., 2000) and allowed computation of isomerizations/s per receptor $\left(\mathrm{Rh}^{\star}\right)$ from stimulus irradiance. Contrasts were computed as $C_{\mathrm{M}}=I(\lambda) S_{\mathrm{M}}^{\mathrm{i}}(\lambda) / \mathrm{Rh}_{\mathrm{M}, \mathrm{bg}}^{*}, C_{\mathrm{S}}=I(\lambda) S_{\mathrm{S}}^{\mathrm{i}}(\lambda) / \mathrm{Rh}_{\mathrm{S}, \mathrm{bg}}^{*}$, and $C_{\mathrm{Rod}}=$ $I(\lambda) S_{\text {Rod }}^{\mathrm{i}}(\lambda) / \mathrm{Rh}_{\text {Rod, bg. }}^{*}$

When $C_{\text {input }}(\lambda) \geq 0$, the LNL model predicted an ON or zero response. When $C_{\text {input }}(\lambda)<0$, the LNL model predicted an OFF response. We used a two-branched nonlinearity that allowed the amplitude of the response to vary with contrast differently for $\mathrm{ON}$ and OFF responses:

$$
\begin{aligned}
& R(\lambda)= \\
& \left\{\begin{array}{ll}
R_{\text {max_ON }} C_{\text {input }}(\lambda)^{\mathrm{n}} /\left(C_{\text {input }}(\lambda)^{\mathrm{n}}+C_{0}^{\mathrm{n}}\right) & C_{\text {input }}(\lambda) \geq 0 \\
R_{\text {max_OfF }}\left|C_{\text {input }}(\lambda)\right|^{\mathrm{n}} /\left(\left|C_{\text {input }}(\lambda)\right|^{\mathrm{n}}+C_{0}^{\mathrm{n}}\right) & C_{\text {input }}(\lambda)<0
\end{array} .\right.
\end{aligned}
$$

The response predicted from Equation B2 was always positive or zero, and had polarity ON or OFF according to the sign of $C_{\text {input }}(\lambda)$. When computing the error between predicted and measured response, we inverted the sign of the predicted response for cases where the predicted and measured polarities differed.

To fit the LNL model to a cell's responses, we used numerical search to find the parameters $w_{\mathrm{M}}^{\mathrm{c}}, w_{\mathrm{S}}^{\mathrm{c}}$, and $w_{\mathrm{Rod}}^{\mathrm{c}}$ in Equation B1, and the parameters $R_{\text {max_ON }}, R_{\text {max_ofF }}, n$, and $C_{\mathbf{0}}$ in Equation $\mathrm{B} 2$ to minimize the root mean squared error between the predictions and measurements.

\section{Computing action spectra from linear responses}

The cell's action spectrum was taken as the weighted sum of the normalized sensitivities of the $M$ cones, $S$ cones, and rods: $S_{\mathrm{M}}^{\mathrm{n}}(\lambda)=S_{\mathrm{M}}^{\mathrm{i}}(\lambda) / \mathrm{Rh}_{\mathrm{M}, \mathrm{bg}}^{*}, S_{\mathrm{S}}^{\mathrm{n}}(\lambda)=S_{\mathrm{S}}^{\mathrm{i}}(\lambda) / \mathrm{Rh}_{\mathrm{S}, \mathrm{bg}}^{*}$, and $S_{\mathrm{Rod}}^{\mathrm{n}}(\lambda)$ $=S_{\text {Rod }}^{\mathrm{i}}(\lambda) / \mathrm{Rh}_{\text {Rod, bg. The normalization accounts for the fact }}^{*}$ that we take the cell's response to be a weighted sum of receptor contrasts rather than a weighted sum of receptor isomerization rates. To plot the measured responses against the action spectrum, we corrected each datum for the cell's nonlinearity:

$$
\begin{aligned}
& R_{\text {linear }}(\lambda)= \\
& \left\{\begin{array}{c}
C_{0} \sqrt[n]{\frac{R_{\mathrm{PSTH}}(\lambda)}{R_{\text {max_ON }}-R_{\mathrm{PSTH}}(\lambda)}} \\
C_{0} \sqrt[n]{\frac{R_{\mathrm{PSTH}}(\lambda)}{R_{\text {max_OFF }}-R_{\mathrm{PSTH}}(\lambda)}}
\end{array}\right. \\
& C_{\text {input }}(\lambda)>0 ; \\
& C_{\text {input }}(\lambda)=0 \text { and measured } \\
& \text { polarity was } \mathrm{ON} \\
& C_{\text {input }}(\lambda)<0 ; \\
& C_{\text {input }}(\lambda)=0 \text { and measured . } \\
& \text { polarity was OFF }
\end{aligned}
$$

In cases where the predicted polarity (based on the sign of $\left.C_{\text {input }}(\lambda)\right)$ differed from the measured polarity, we inverted the sign of $R_{\text {linear }}(\lambda)$.

\section{Appendix C: DOG receptive field model}

We used a DOG receptive field model in two dimensions (Enroth-Cugell and Robson, 1966; Derrington and Lennie, 1984; Solomon et al., 2005) to describe the spatial structure of the receptive fields of S/M opponent cells. For each cell, we assumed the receptive field $(\mathrm{RF})$ was the weighted difference between a concentric Gaussian center and surround. The normalized spatial profiles of the center and surround were as follows: 


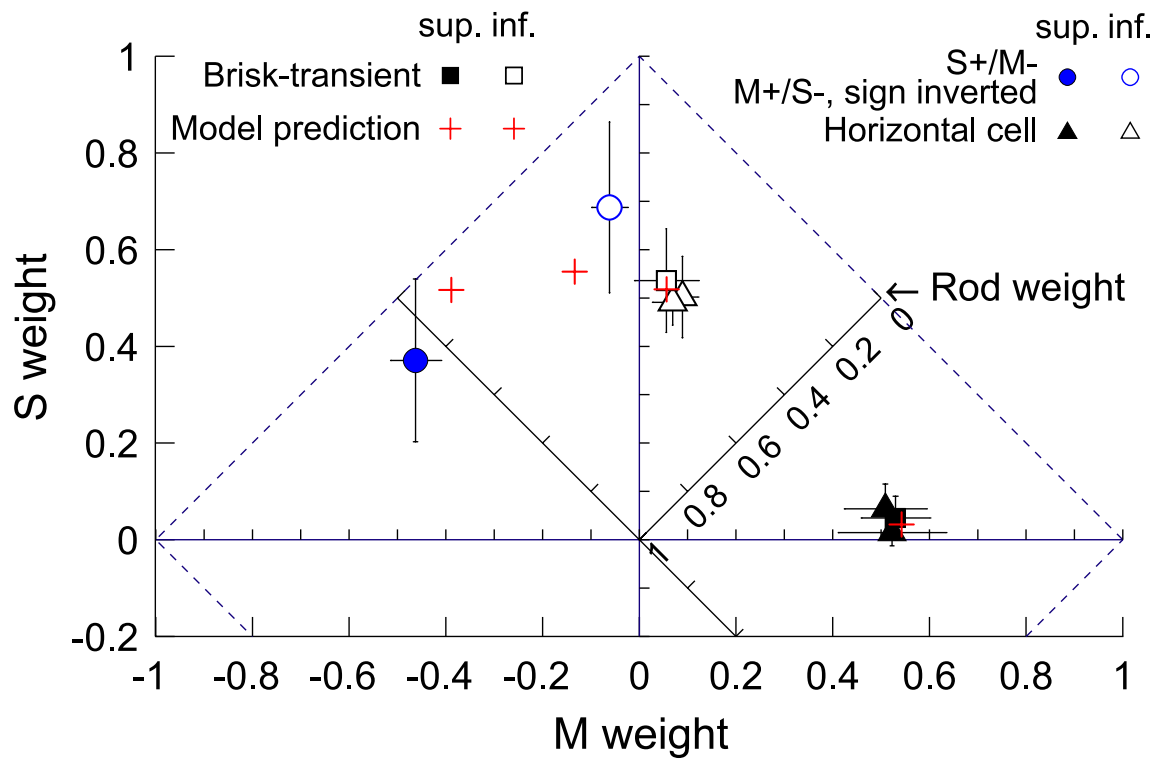

Figure 11. Functional model predictions. Modeling results in the same format as Figure 6. Solid and open circles show the average photopigment weights for opponent cells from superior and inferior retina (for superior retina, weights were averaged across $S+/ M-$ and $M+/ S-$ opponent cells by inverting the sign of the weights from the $M+/ S-$ opponent cells). Triangles ( $\pm S D$ ) show averaged data from horizontal cells in superior (solid) and inferior retina (open), with two triangles for each retinal location representing results from two measurement protocols (Yin et al., 2006). Squares ( \pm SD) show averaged data from brisk-transient ganglion cells (superior retina, solid; inferior retina, open). The red plusses show the photopigment weights derived from the model fit (see Table 1).

Here, $\sigma^{\text {Center }}$ and $\sigma^{\text {Surround }}$ determine the spatial extent of the center and surround and $r$ is distance from the center of the receptive field. Because we did not observe any shift in response phase with stimulus size, we did not include a parameter to describe a relative delay in the response of the surround with respect to the center (Enroth-Cugell et al., 1983).

We further assumed that both the receptive field center and surround received a weighted combination of $M$ and $S$ inputs, the relative strengths of which were described by four non-negative weights: $w_{\mathrm{M}}^{\text {Center }}, w_{\mathrm{S}}^{\text {Center }}, w_{\mathrm{M}}^{\text {Surround }}$, and $w_{\mathrm{S}}^{\text {Surround }}$. The constraint of non-negativity on $w_{\mathrm{M}}^{\text {Center }}$ and $w_{\mathrm{S}}^{\text {Center }}$ means that the $\mathrm{M}$ and $\mathrm{S}$ inputs contributed to center with the same sign as each other; the constraint of non-negativity on $w_{\mathrm{M}}^{\text {Surround }}$ and $w_{\mathrm{S}}^{\text {Surround }}$ means that the two inputs also had the same sign as each other for the surround. Although we could have used a more general form for the spatio-chromatic properties of the cell, the form we used captures the notion of center-surround antagonism and provided a good fit to the area summation data. The overall opponency of the cell was incorporated in the model by taking the difference between center and surround.

To account for the rod input to the cell, we assumed that rod signal flowed to cones through rod-cone gap junctions, with a coupling strength of $K_{\text {Rod-Cone }}$. Therefore the relative strengths of rod inputs to the center and surround were described as follows:

$$
\left\{\begin{array}{l}
w_{\text {Rod }}^{\text {Center }}=K_{\text {Rod-Cone }}\left(w_{\mathrm{M}}^{\text {Center }}+w_{\mathrm{S}}^{\text {Center }}\right) \\
w_{\text {Rod }}^{\text {Surround }}=K_{\text {Rod-Cone }}\left(w_{M}^{\text {Surround }}+w_{\mathrm{S}}^{\text {Surround }}\right)
\end{array} .\right.
$$

\section{Appendix D: functional model for photopigment weights}

The model is characterized by 4 parameters. These are $(1) f_{\mathrm{S}}$, the proportion of genuine $S$ cones (Haverkamp et al., 2005), taken to be constant across the retina; (2) $g_{\mathrm{s}}$, the gain of signals from the genuine $S$ cones through the $S$ cone bipolar to $S / M$ opponent ganglion cells, expressed relative to the gain for these same signals as they reach nonopponent cells; (3) $c_{\mathrm{R}-\mathrm{C}}$, the strength of rod coupling to cones (Lee et al., 2003; Hornstein et al., 2005; Verweij et al., 2008), taken to be independent of cone type (Ahnelt et al., 1990) and retinal location; and (4) $\beta$, the proportion of M-pigment coexpressed in the cones that are nongenuine $S$ cones in inferior retina. (This proportion is fixed at $\beta=1$ in superior retina.)

\section{Model description for nonopponent cells}

We start with the formula for the $\mathrm{S}$ weight for nonopponent cells (horizontal and brisk-transient ganglion cells) in superior retina. Here the strength of $\mathrm{S}$ input relative to $\mathrm{M}$ input (excluding rods) is given directly by $f_{\mathrm{S}} /\left(1-f_{\mathrm{S}}\right)$. This is because we assume that the gain from cones to nonopponent cells is the same for all cone types and because the $S$ and $\mathrm{M}$ pigments are assumed to be completely segregated within separate cones. There is also a rod weight, which we take directly as the parameter $c_{\mathrm{R}-\mathrm{C}}$. This convention defines the units of $c_{\mathrm{R}-\mathrm{C}}$ in terms of the strength of rod input per cone. This leads to the expression for the relative $S$ weight as follows:

$$
\underset{\mathrm{S}}{\substack{\text { sunerior } \\ \text { nonopont }}}=\frac{f_{\mathrm{S}}}{f_{\mathrm{S}}+\left(1-f_{\mathrm{S}}\right)+c_{\mathrm{R}-\mathrm{C}}}=\frac{f_{\mathrm{S}}}{1+c_{\mathrm{R}-\mathrm{C}}}
$$

for nonopponent cells in superior retina.

We can generalize Equation D1 for the case where S and M 
pigment are both expressed in the nongenuine $S$ cones, as is the case for inferior retina.

$$
\begin{array}{r}
w_{\mathrm{S}}^{\text {nonopponent }}=\frac{f_{\mathrm{S}}+(1-\beta)\left(1-f_{\mathrm{S}}\right)}{f_{\mathrm{S}}+(1-\beta)\left(1-f_{\mathrm{S}}\right)+\beta\left(1-f_{\mathrm{S}}\right)+c_{\mathrm{R}-\mathrm{C}}} \\
=\frac{1-\beta\left(1-f_{\mathrm{S}}\right)}{1+c_{\mathrm{R}-\mathrm{C}}}
\end{array}
$$

Here the quantity $(1-\beta)$ is the strength of $S$ opsin input from nongenuine $S$ cones. Note that Equation D2 reduces to Equation D1 when $\beta=1$.

In analogy to Equation D2, we also have expressions for the relative $\mathrm{M}$ and rod weights to nonopponent cells in both superior and inferior retina.

$$
\begin{array}{r}
w_{\mathrm{M}}^{\text {nonopponent }}=\frac{\beta\left(1-f_{\mathrm{S}}\right)}{f_{\mathrm{S}}+(1-\beta)\left(1-f_{\mathrm{S}}\right)+\beta\left(1-f_{\mathrm{S}}\right)+c_{\mathrm{R}-\mathrm{C}}} \\
=\frac{\beta\left(1-f_{\mathrm{S}}\right)}{1+c_{\mathrm{R}-\mathrm{C}}}
\end{array}
$$

and

$$
w_{\text {Rod }}^{\text {nonopponent }}=\frac{c_{\mathrm{R}-\mathrm{C}}}{1+c_{\mathrm{R}-\mathrm{C}}} .
$$

Note that the weights obtained through Equations D2, D3, and D4 were normalized so that their sum was one.

\section{Model description for opponent cells}

The formulae for photopigment weights for opponent cells are based on the same ideas, but take into account the amplification of signals from genuine $S$ cones. Note that this amplification is applied both to the $S$ opsin signal for these cones and also to the rod signal that passes through these cones. We obtain for the magnitude of the cone weights the following:

$$
\begin{aligned}
& \left|w_{\mathrm{S}}^{\text {opponent }}\right|= \\
& \frac{g_{\mathrm{S}} f_{\mathrm{S}}-(1-\beta)\left(1-f_{\mathrm{S}}\right)}{g_{\mathrm{S}} f_{\mathrm{S}}-(1-\beta)\left(1-f_{\mathrm{S}}\right)+\beta\left(1-f_{\mathrm{S}}\right)+\left|c_{\mathrm{R}-\mathrm{C}_{\mathrm{S}}} f_{\mathrm{S}}-c_{\mathrm{R}-\mathrm{C}}\left(1-f_{\mathrm{S}}\right)\right|} \\
& =\frac{g_{\mathrm{S}} f_{\mathrm{S}}-(1-\beta)\left(1-f_{\mathrm{S}}\right)}{g_{\mathrm{S}} f_{\mathrm{S}}-(1-2 \beta)\left(1-f_{\mathrm{S}}\right)+c_{\mathrm{R}-\mathrm{C}}\left|g_{\mathrm{S}} f_{\mathrm{S}}-\left(1-f_{\mathrm{S}}\right)\right|}, \\
& \left|w_{\mathrm{M}}^{\text {opponent }}\right|= \\
& \frac{\beta\left(1-f_{\mathrm{S}}\right)}{g_{\mathrm{S}} f_{\mathrm{S}}-(1-\beta)\left(1-f_{\mathrm{S}}\right)+\beta\left(1-f_{\mathrm{S}}\right)+\left|c_{\mathrm{R}-\mathrm{C}} g_{\mathrm{S}} f_{\mathrm{S}}-c_{\mathrm{R}-\mathrm{C}}\left(1-f_{\mathrm{S}}\right)\right|} \\
& =\frac{\beta\left(1-f_{\mathrm{S}}\right)}{g_{\mathrm{S}} f_{\mathrm{S}}-(1-2 \beta)\left(1-f_{\mathrm{S}}\right)+c_{\mathrm{R}-\mathrm{C}}\left|g_{\mathrm{S}} f_{\mathrm{S}}-\left(1-f_{\mathrm{S}}\right)\right|},
\end{aligned}
$$

and for the rod weight

$$
\begin{aligned}
& w_{\text {Rod }}^{\text {opponent }}= \\
& \frac{c_{\mathrm{R}-\mathrm{C}} g_{\mathrm{S}} f_{\mathrm{S}}-c_{\mathrm{R}-\mathrm{C}}\left(1-f_{\mathrm{S}}\right)}{g_{\mathrm{S}} f_{\mathrm{S}}-(1-\beta)\left(1-f_{\mathrm{S}}\right)+\beta\left(1-f_{\mathrm{S}}\right)+\left|c_{\mathrm{R}-\mathrm{C}} g_{\mathrm{S}} f_{\mathrm{S}}-c_{\mathrm{R}-\mathrm{C}}\left(1-f_{\mathrm{S}}\right)\right|} \\
& =\frac{c_{\mathrm{R}-\mathrm{C}}\left[g_{\mathrm{S}} f_{\mathrm{S}}-\left(1-f_{\mathrm{S}}\right)\right]}{g_{\mathrm{S}} f_{\mathrm{S}}-(1-2 \beta)\left(1-f_{\mathrm{S}}\right)+c_{\mathrm{R}-\mathrm{C}}\left|g_{\mathrm{S}} f_{\mathrm{S}}-\left(1-f_{\mathrm{S}}\right)\right|}
\end{aligned}
$$

The sign of $w_{S}^{\text {opponent }}$ was positive for $\mathrm{S}+/ \mathrm{M}-$ cells and negative for $\mathrm{M}+/ \mathrm{S}-$ cells, and vice-versa for the sign of $w_{\mathrm{M}}^{\text {opponent }}$. The sign of the rod weight given by Equation D7 is relative to the sign of $w_{\mathrm{S}}^{\text {opponent }}$ : the signed value computed through Equation D7 was multiplied by the sign of $w_{S}^{\text {opponent }}$. The sum of the magnitudes of the weights obtained through Equations D5-D7 is one. In fitting the model, we averaged the weights of $\mathrm{S}+/ \mathrm{M}-$ and $\mathrm{M}+/ \mathrm{S}-$ by inverting the sign of the weights measured for $\mathrm{M}+/ \mathrm{S}-$ cells.

\section{Fitting the model parameters}

Equations D2-D7 predict the photopigment weights of opponent and nonopponent cells in both superior and inferior retina as a function of the four model parameters. We fixed $f_{S}$ at $5.5 \%$ based on our immunostaining data from superior retina [this number is given as rounded to $6 \%$ in the work of Yin et al. (2006) and elsewhere in this study]. We used numerical search to find the values of the remaining three parameters that provided the best fit (in a least squares sense) to the mean values for each cell type, as measured here and in our previous study (Yin et al., 2006). In determining the mean values we combined $\mathrm{S}+/ \mathrm{M}-$ and $\mathrm{M}+/ \mathrm{S}-$ opponent cells, inverting the sign of weights for the $M+/ S-$ cells.

\section{References}

Ahnelt P, Keri C, Kolb H (1990) Identification of pedicles of putative bluesensitive cones in the human retina. J Comp Neurol 293:39-53.

Ahnelt PK, Kolb H (2000) The mammalian photoreceptor mosaic-adaptive design. Prog Retin Eye Res 19:711-777.

Arrese CA, Beazley LD, Neumeyer C (2006) Behavioural evidence for marsupial trichromacy. Curr Biol 16:R193-R194.

Asher M, de Oliveira ES, Sachser N (2004) Social system and spatial organization of wild guinea pigs (Cavia aperea) in a natural population. J Mammal 85:788-796.

Berson DM, Dunn FA, Takao M (2002) Phototransduction by retinal ganglion cells that set the circadian clock. Science 295:1070-1073.

Bloomfield SA, Dacheux RF (2001) Rod vision: pathways and processing in the mammalian retina. Prog Retin Eye Res 20:351-384.

Borghuis BG, Ratliff CP, Smith RG, Sterling P, Balasubramanian V (2008) Design of a neuronal array. J Neurosci 28:3178-3189.

Caldwell JH, Daw NW (1978) New properties of rabbit retinal ganglion cells. J Physiol 276:257-276.

Calkins DJ, Tsukamoto Y, Sterling P (1998) Microcircuitry and mosaic of a blue-yellow ganglion cell in the primate retina. J Neurosci 18:3373-3385.

Cassini MH (1991) Foraging under predation risk in the wild guinea pig Cavia aperea. Oikos 62:20-24.

Cassini MH, Galante ML (1992) Foraging under predation risk in the wild guinea pig: the effect of vegetation height on habitat utilization. Ann Zool Fenn 29:285-290.

Chatterjee S, Callaway EM (2002) S cone contributions to the magnocellular visual pathway in macaque monkey. Neuron 35:1135-1146.

Chichilnisky EJ (2001) A simple white noise analysis of neuronal light responses. Network 12:199-213.

Chichilnisky EJ, Kalmar RS (2002) Functional asymmetries in ON and OFF ganglion cells of primate retina. J Neurosci 22:2737-2747.

Cleland BG, Levick WR (1974) Properties of rarely encountered types of ganglion cells in the cat's retina and an overall classification. J Physiol 240:457-492.

Cowing JA, Arrese CA, Davies WL, Beazley LD, Hunt DM (2008) Cone visual pigments in two marsupial species: the fat-tailed dunnart (Sminthopsis crassicaudata) and the honey possum (Tarsipes rostratus). Proc Biol Sci 275:1491-1499.

Dacey DM (1993) Morphology of a small-field bistratified ganglion cell type in the macaque and human retina. Vis Neurosci 10:1081-1098.

Dacey DM (1996) Circuitry for color coding in the primate retina. Proc Natl Acad Sci U S A 93:582-588.

Dacey DM (2000) Parallel pathways for spectral coding in primate retina. Annu Rev Neurosci 23:743-775. 
Dacey DM, Lee BB (1994) The 'blue-on' opponent pathway in primate retina originates from a distinct bistratified ganglion cell type. Nature 367:731-735.

Dacey DM, Packer OS (2003) Colour coding in the primate retina: diverse cell types and cone-specific circuitry. Curr Opin Neurobiol 13:421-427.

Dacey DM, Lee BB, Stafford DK, Pokorny J, Smith VC (1996) Horizontal cells of the primate retina: cone specificity without spectral opponency. Science 271:656-659.

Dacey DM, Liao HW, Peterson BB, Robinson FR, Smith VC, Pokorny J, Yau KW, Gamlin PD (2005) Melanopsin-expressing ganglion cells in primate retina signal colour and irradiance and project to the LGN. Nature 433:749-754.

Davenport CM, Detwiler PB, Dacey DM (2008) Effects of pH buffering on horizontal and ganglion cell light responses in primate retina: evidence for the proton hypothesis of surround formation. J Neurosci 28:456-464.

Derrington AM, Lennie P (1984) Spatial and temporal contrast sensitivities of neurones in lateral geniculate nucleus of macaque. J Physiol 357:219-240.

Do-Nascimento JL, Do-Nascimento RS, Damasceno BA, Silveira LC (1991) The neurons of the retinal ganglion cell layer of the guinea pig: quantitative analysis of their distribution and size. Braz J Med Biol Res 24:199-214.

Ekesten B, Gouras P (2005) Cone and rod inputs to murine retinal ganglion cells: Evidence of cone opsin specific channels. Vis Neurosci 22:893-903.

Ekesten B, Gouras P, Yamamoto S (2000) Cone inputs to murine retinal ganglion cells. Vision Res 40:2573-2577.

Enroth-Cugell C, Robson JG (1966) The contrast sensitivity of retinal ganglion cells of the cat. J Physiol 187:517-552.

Enroth-Cugell C, Robson JG, Schweitzer-Tong DE, Watson AB (1983) Spatio-temporal interactions in cat retinal ganglion cells showing linear spatial summation. J Physiol 341:279-307.

Field GD, Sher A, Gauthier JL, Greschner M, Shlens J, Litke AM, Chichilnisky EJ (2007) Spatial properties and functional organization of small bistratified ganglion cells in primate retina. J Neurosci 27:13261-13272.

Ghosh KK, Grünert U (1999) Synaptic input to small bistratified (blue-ON) ganglion cells in the retina of a New World monkey, the marmoset Callithrix jacchus. J Comp Neurol 413:417-428.

Ghosh KK, Martin PR, Grünert U (1997) Morphological analysis of the blue cone pathway in the retina of a New World monkey, the marmoset Callithrix jacchus. J Comp Neurol 379:211-225.

Govardovskii VI, Fyhrquist N, Reuter T, Kuzmin DG, Donner K (2000) In search of the visual pigment template. Vis Neurosci 17:509-528.

Grivich MI, Sher A, Petrusca D, Field GD, Shlens J, Gauthier JL, Chichilnisky EJ, Litke AM (2005) Classification of guinea pig retinal ganglion cells using large-scale multielectrode recordings. Soc Neurosci Abstr 31:246.10.

Haverkamp S, Wässle H, Duebel J, Kuner T, Augustine GJ, Feng G, Euler T (2005) The primordial, blue-cone color system of the mouse retina. J Neurosci 25:5438-5445.

Hemmi JM, James A, Taylor WR (2002) Color opponent retinal ganglion cells in the tammar wallaby retina. J Vis 2:608-617.

Herr S, Klug K, Sterling P, Schein S (2003) Inner S-cone bipolar cells provide all of the central elements for $\mathrm{S}$ cones in macaque retina. J Comp Neurol 457:185-201.

Hornstein EP, Verweij J, Li PH, Schnapf JL (2005) Gap-junctional coupling and absolute sensitivity of photoreceptors in macaque retina. J Neurosci 25:11201-11209.

Jacobs GH (1993) The distribution and nature of colour vision among the mammals. Biol Rev Camb Philos Soc 68:413-471.

Jacobs GH, Deegan JF 2nd (1994) Spectral sensitivity, photopigments, and color vision in the guinea pig (Cavia porcellus). Behav Neurosci 108:993-1004.

Jacobs GH, Blakeslee B, Tootell RB (1981) Color-discrimination tests on fibers in ground squirrel optic nerve. J Neurophysiol 45:903-914.

Jacobs GH, Williams GA, Cahill H, Nathans J (2007) Emergence of novel color vision in mice engineered to express a human cone photopigment. Science 315:1723-1725.

Kao YH, Sterling P (2006) Displaced GAD65 amacrine cells of the guinea pig retina are morphologically diverse. Vis Neurosci 23:931-939.

Klug K, Herr S, Ngo IT, Sterling P, Schein S (2003) Macaque retina contains an S-cone OFF midget pathway. J Neurosci 23:9881-9887.

Kong JH, Fish DR, Rockhill RL, Masland RH (2005) Diversity of ganglion cells in the mouse retina: unsupervised morphological classification and its limits. J Comp Neurol 489:293-310.

Kouyama N, Marshak DW (1992) Bipolar cells specific for blue cones in the macaque retina. J Neurosci 12:1233-1252.

Lee EJ, Han JW, Kim HJ, Kim IB, Lee MY, Oh SJ, Chung JW, Chun MH (2003) The immunocytochemical localization of connexin 36 at rod and cone gap junctions in the guinea pig retina. Eur J Neurosci 18:2925-2934.

Lee PM (1989) Bayesian statistics. London: Oxford UP.

Li W, DeVries SH (2006) Bipolar cell pathways for color and luminance vision in a dichromatic mammalian retina. Nat Neurosci 9: 669-675

MacNeil MA, Gaul PA (2008) Biocytin wide-field bipolar cells in rabbit retina selectively contact blue cones. J Comp Neurol 506:6-15.

Mancuso K, Neitz J, Hauswirth WW, Connor TB, Neitz M (2007) Gene therapy treatment of color blindness in adult primates [Abstract]. J Vis $7: 15$.

Mariani AP (1984) Bipolar cells in monkey retina selective for the cones likely to be blue-sensitive. Nature 308:184-186.

Martin PR, Szmajda BA, Grunert U (2007) Projection patterns and morphology of koniocellular pathway ganglion cells in marmoset retina. Invest Ophthalmol Vis Sci 48:3177.

Michael CR (1966) Receptive fields of opponent color units in the optic nerve of the ground squirrel. Science 152:1095-1097.

Müller F, Wässle H, Voigt T (1988) Pharmacological modulation of the rod pathway in the cat retina. J Neurophysiol 59:1657-1672.

Nikonov SS, Kholodenko R, Lem J, Pugh EN Jr (2006) Physiological features of the S- and M-cone photoreceptors of wild-type mice from singlecell recordings. J Gen Physiol 127:359-374.

Osorio D, Vorobyev M (2005) Photoreceptor spectral sensitivities in terrestrial animals: adaptations for luminance and colour vision. Proc Biol Sci 272:1745-1752.

Packer O, Verweij J, Schnapf JL, Dacey DM (2007) Primate S cones have blue-yellow opponent receptive fields. Invest Ophthalmol Vis Sci 48:2849.

Peichl L (2005) Diversity of mammalian photoreceptor properties: adaptations to habitat and lifestyle? Anat Rec A Discov Mol Cell Evol Biol 287:1001-1012.

Peichl L, Behrmann G, Kröger RH (2001) For whales and seals the ocean is not blue: a visual pigment loss in marine mammals. Eur J Neurosci 13:1520-1528.

Rockhill RL, Daly FJ, MacNeil MA, Brown SP, Masland RH (2002) The diversity of ganglion cells in a mammalian retina. J Neurosci 22:3831-3843.

Röhlich P, van Veen T, Szél A (1994) Two different visual pigments in one retinal cone cell. Neuron 13:1159-1166.

Schein S, Sterling P, Ngo IT, Huang TM, Herr S (2004) Evidence that each S cone in macaque fovea drives one narrow-field and several wide-field blue-yellow ganglion cells. J Neurosci 24:8366-8378.

Schiviz AN, Ruf T, Kuebber-Heiss A, Schubert C, Ahnelt PK (2008) Retinal cone topography of artiodactyl mammals: influence of body height and habitat. J Comp Neurol 507:1336-1350.

Sharpe LT, Stockman A (1999) Rod pathways: the importance of seeing nothing. Trends Neurosci 22:497-504.

Silveira LC, Lee BB, Yamada ES, Kremers J, Hunt DM, Martin PR, Gomes FL (1999) Ganglion cells of a short-wavelength-sensitive cone pathway in New World monkeys: morphology and physiology. Vis Neurosci 16:333-343.

Solomon SG, Lee BB, White AJ, Rüttiger L, Martin PR (2005) Chromatic organization of ganglion cell receptive fields in the peripheral retina. J Neurosci 25:4527-4539.

Sterling P (1983) Microcircuitry of the cat retina. Annu Rev Neurosci 6:149-185. 
Sterling P (2004) How retinal circuits optimize the transfer of visual information. In: Visual neurosciences (Chalupa LM, Werner JS, eds), pp 234259. Cambridge, MA: MIT.

Szél A, Röhlich P, Caffé AR, van Veen T (1996) Distribution of cone photoreceptors in the mammalian retina. Microsc Res Tech 35:445-462.

Szél A, Lukáts A, Fekete T, Szepessy Z, Röhlich P (2000) Photoreceptor distribution in the retinas of subprimate mammals. J Opt Soc Am A Opt Image Sci Vis 17:568-579.

Verweij J, Li PH, Packer O, Dacey DM, Schnapf JL (2008) Primate blue cones receive rod input. Invest Ophthalmol Vis Sci 49:3250.

Wassle H (2004) Parallel processing in the mammalian retina. Nat Rev Neurosci 5:747-757.
Wiesel TN, Hubel DH (1966) Spatial and chromatic interactions in the lateral geniculate body of the rhesus monkey. J Neurophysiol 29:1115-1156.

Xu Y, Vasudeva V, Vardi N, Sterling P, Freed MA (2008) Different types of ganglion cell share a synaptic pattern. J Comp Neurol 507:1871-1878.

Yin L, Smith RG, Sterling P, Brainard DH (2006) Chromatic properties of horizontal and ganglion cell responses follow a dual gradient in cone opsin expression. J Neurosci 26:12351-12361.

Zaghloul KA, Boahen K, Demb JB (2003) Different circuits for ON and OFF retinal ganglion cells cause different contrast sensitivities. J Neurosci 23: 2645-2654. 